\title{
Intensidade da atividade tectônica na porção emersa da Bacia Paraíba e em- basamento cristalino adjacente, Nordeste do Brasil
}

\author{
Clódis de Oliveira ANDRADES FILHO ${ }^{1,2}$ \& Dilce de Fátima ROSSETTI ${ }^{1,3}$
}

\author{
1. Instituto de Geociências, Universidade de São Paulo. Rua do Lago, 562, Cidade Universitária, CEP 05508-080, São Paulo, SP, \\ Brasil. E-mail: andradesfilho@usp.br. \\ 2. Universidade Estadual do Rio Grande do Sul. Av. Assis Brasil, 842, CEP 95400-000, São Francisco de Paula, RS, Brasil. E-mail: \\ clodis-filho@uergs.edu.br. \\ 3. Divisão de Sensoriamento Remoto, Instituto Nacional de Pesquisas Espaciais. Caixa Postal 515, CEP 12227-010, São José dos \\ Campos, SP, Brasil. E-mail: rossetti@dsr.inpe.br.
}

Recebido em 02/2014. Aceito para publicação em 07/2015.

Versão online publicada em 19/08/2015 (www.pesquisasemgeociencias.ufrgs.br)

\begin{abstract}
Resumo - Estudos realizados em diferentes contextos geomorfológicos da Terra têm demonstrado a eficácia da aplicação de dados geomorfométricos extraídos a partir de modelos digitais de elevação para a identificação de feições do terreno sugestivas de deformação tectônica. Este estudo aplica índices geomorfométricos na avaliação da intensidade tectônica de depósitos sedimentares da porção emersa da Bacia Paraíba e do embasamento cristalino adjacente, nordeste do Brasil. A partir da base digital da rede de drenagem e do modelo digital de elevação da Shuttle Radar Topography Mission (SRTM) foram empregados os índices: relação declividade-extensão (RDE), fator assimétrico $(A f)$, integral hipsométrica $(\mathrm{Hi})$ e sinuosidade de frente de montanha ( $\mathrm{Smf}$ ). Os resultados possibilitaram distinguir e espacializar classes de intensidade de deformação tectônica por meio do índice de atividade tectônica relativa (Iat). Os dados revelaram tectonismo mais intenso em unidades sedimentares neógenas e quaternárias localizadas na porção nordeste da área estudada. Palavras-chave: índices geomorfométricos, Neógeno, Quaternário, SRTM.
\end{abstract}

\begin{abstract}
Spatialization of tectonic intensity in the onshore portion of the Paraíba BaSIN AND ADJACENT CRYSTALLINE BASEMENT, NORTHEASTERN BRAZIL. Studies conducted in different geomorphological contexts of the Earth have demonstrated efficiency in the application of geomorphometric data extracted from digital elevation models for the identification of terrain features suggestive of tectonic deformation. This study applies geomorphometric indices for the evaluation of the tectonic intensity of sedimentary deposits of the onshore portion of the Paraíba Basin and of the adjacent crystalline basement, northeastern Brazil. The following indices were applied with basis on digital drainage network and digital elevation model of the Shuttle Radar Topography Mission (SRTM): slope-length ratio (SL), asymmetric factor (Af), hypsometric integral (Hi) and mountain-front sinuosity (Smf). The results enabled to distinguish and to spacialize classes of tectonic deformation intensity through the tectonic intensity index (Iat). The data revealed more intense tectonism in Neogene and Quaternary sedimentary units located in the northeastern portion of the study area.
\end{abstract}

Keywords: geomorphometric indexes, Neogene, Quaternary, SRTM.

\section{Introdução}

Estudos geológicos e geomorfológicos em escalas regionais apresentaram importantes avanços com a utilização de dados de sensoriamento remoto (e.g., Grohmann, 2004; El Hamdouni et al., 2008). Em particular, imagens ópticas têm larga aplicação em áreas áridas e semi-áridas (e.g., Gomez et al., 2005), porém seu uso tem sido limitado em áreas tropicais úmidas, onde a cobertura vegetal e de nuvens é frequente. Este é o caso do território bra- sileiro, onde o radar de abertura sintética (SAR) tem tido melhor sucesso em aplicações geológicas. Estas aplicações podem ser potencializadas com o uso de radar de abertura sintética interferométrico - InSAR (e.g., Parcharidis et al., 2009), que possibilita a geração de modelos digitais de elevação (MDE), fundamentais na geração de informações do relevo a partir da geomorfometria (Pike, 2000). Vários estudos têm demonstrado a aplicação de variáveis geomorfométricas extraídas a partir de MDE para a identificação de feições do terreno su- 
gestivas de deformação tectônica (e.g., Jordan et al., 2005; El Hamdouni et al., 2008). Estudos desta natureza têm sido recentemente impulsionados pela ampla distribuição de dados topográficos digitais, como os modelos interferométricos derivados da missão SRTM (Shuttle Radar Topography Mission) (Rabus et al., 2003).

Dentre as variáveis geomorfométricas, o índice relação declividade-extensão $(R D E)$, fator assimétrico ( $A f$ ), integral hipsométrica $(H i)$ e sinuosidade de frente de montanha $(S m f)$ têm sido enfatizados na discriminação de áreas sob influência de deformação tectônica, cujos registros estão impressos no relevo da paisagem atual (e.g., Bull \& Mc Fadden, 1977; El Hamdouni et al., 2008; Troiani \& Della Seta, 2008). Este tipo de investigação auxilia na reconstituição do arcabouço estrutural, por permitir o reconhecimento de estruturas tectônicas, como falhas, fraturas e dobras, desenvolvidas em diferentes momentos do passado geológico. Além disso, a aplicação de índices morfométricos favorece a detecção de estruturas muitas vezes imperceptíveis em campo, particularmente em áreas com carência de exposições de rochas, possibilitando sua caracterização em amplas faixas de terreno.

O objetivo deste trabalho é a aplicação de índices morfométricos a partir dos dados MDE-SRTM, com intuito de mapear a intensidade da influência tectônica na cobertura sedimentar da Bacia Paraíba e no embasamento precambriano adjacente. Um número crescente de publicações tem demonstrado que a costa nordeste brasileira, apesar de ocorrer em uma margem passiva, permaneceu em relativa atividade tectônica após o estabelecimento do rifte intercontinental que deu origem às bacias marginais no Juro-Cretáceo (e.g., Bezerra, 1998; Bezerra et al., 1998, 2001, 2008, 2014; Bezerra \& Vita-Finzi, 2000; Morais Neto \& Alkmin, 2001; Barreto et al., 2002; Brito Neves et al., 2004; Nogueira et al., 2006). Além disto, abalos sísmicos, provavelmente relacionados à reativação de falhas, têm sido cada vez mais frequentes na região (Ferreira et al., 1998; Marotta, 2013). A Bacia Paraíba merece destaque por ter permanecido tectonicamente ativa por mais tempo relativamente às demais bacias marginais do nordeste brasileiro, representando a última ponte de ligação das placas sulamericana e africana (Matos, 1992; Françolin et al., 1994; Oliveira \& Gomes, 1996). No entanto, com poucas exceções (e.g., Andrades Filho \& Rossetti, 2012ab), ainda são poucos os estudos de detalhe nessa área, principalmente no que diz respeito à avaliação da influência da tectônica nas formas encontradas na paisagem, bem como seus significados. Em particular, análises quantitativas que permitam uma caracterização morfoestrutural na bacia são ainda inexistentes, apesar de métodos quantitativos terem sido sugeridos como eficientes na análise morfoestrutural de diversos contextos geológicos associados diretamente à atividade tectônica (e.g., Bull \& Mc Fadden, 1977; Keller \& Pinter, 2002; Grohmann, 2004; Etchebehere et al., 2006; El Hamdouni et al., 2008; Troiani \& Della Seta, 2008).

\section{2 Área, materiais e métodos}

A área de estudo, localizada na região nordeste do Brasil, abrange a porção central da Bacia Paraíba e o embasamento cristalino adjacente (Fig. 1). Tendo como referência a capital do Estado da Paraíba, João Pessoa, a área estende-se aproximadamente $38 \mathrm{~km}$ para oeste e $42 \mathrm{~km}$ para sul (Fig. 1). As unidades geográficas consideradas no estudo incluem 22 sub-bacias do conjunto de bacias dos rios Goiana, Gramame, Dois Rios, Baixo Paraíba, bem como dos rios da faixa litorânea. Nestas estão incluídas as unidades denominadas no mapa-índice pelo número 4 (Goiana), 9 (Dois Rios), e 10 (Gramame) (Fig. 2). Essa rede de drenagem ocorre sobre uma área de preenchimento sedimentar representado em superfície pelas formações Gramame e Barreiras, bem como pelos sedimentos pós-Barreiras e aluviões recentes, além do embasamento cristalino a oeste (Fig. 3) (Andrades Filho et al., 2014).

\subsection{Aplicação de índices geomorfométricos}

A análise quantitativa foi realizada em sistema de informações geográficas (SIG), com base nos aplicativos SPRING e ArcGIS, e baseada em quatro índices morfométricos: relação declividade-extensão $(R D E)$, fator assimétrico $(A f)$, integral hipsométrica $(\mathrm{Hi})$, e sinuosidade de faces de montanha $(S m f)$. Além desses índices, utilizou-se um índice combinatório denominado índice de atividade tectônica relativa (Iat), que integrou informação dos demais.

Os índices morfométricos foram calculados com base em informações derivadas do MDE-SRTM-3", disponibilizado em sua 4⿳亠丷厂 versão a partir do endereço eletrônico http://srtm.csi.cgiar. org, e da rede de drenagem de 22 bacias hidrográficas, definidas de forma semi-automática. A análise dos índices baseou-se, também, na integração com o mapa geológico apresentado em Rossetti et al. (2011a). 


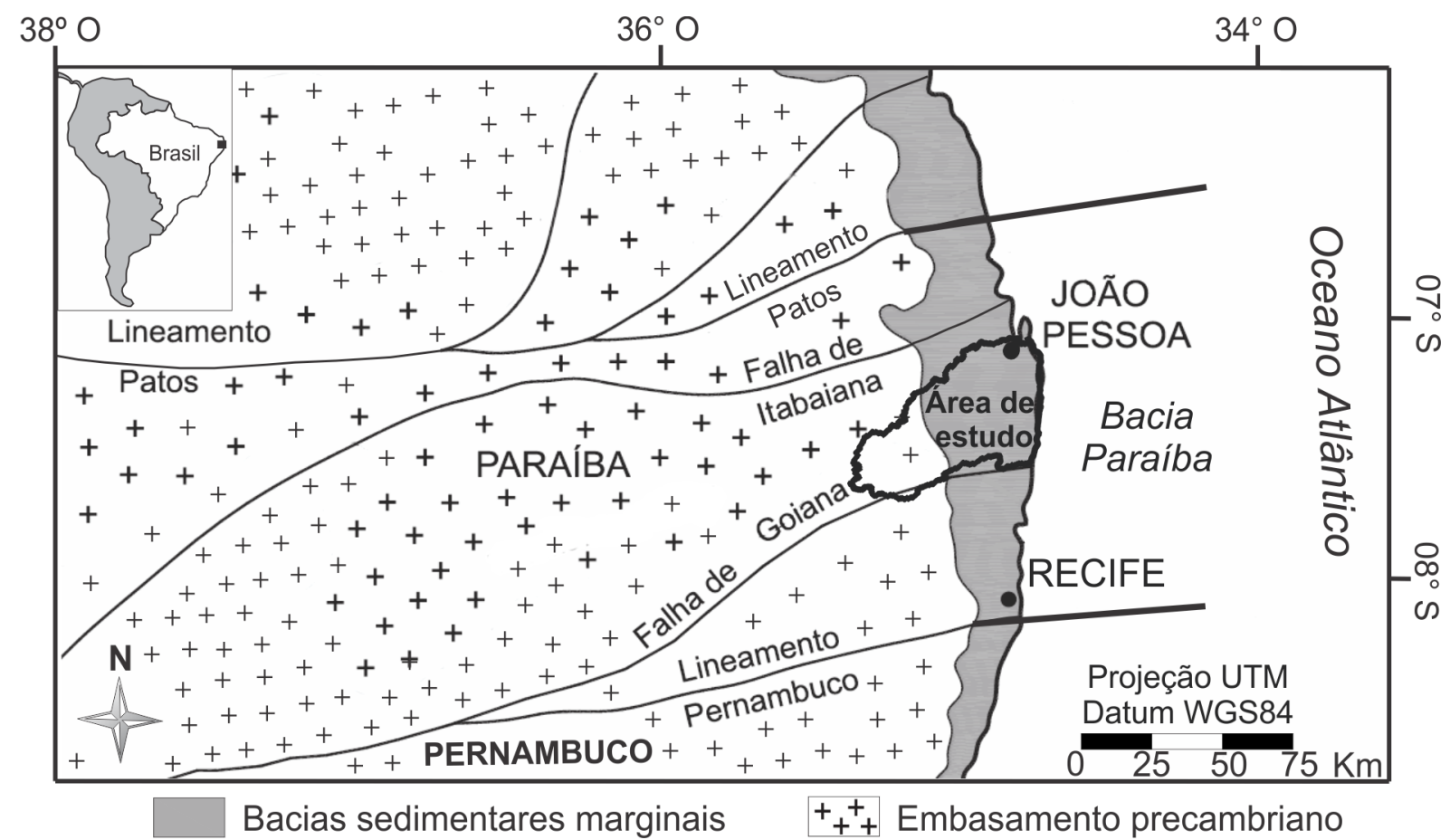

Figura 1. Área de estudo abrangendo parte das bacias sedimentares marginais do Nordeste do Brasil e do embasamento cristalino adjacente (retângulo tracejado = área de estudo na porção leste dos estados da Paraíba e Pernambuco). Modificado a partir de Barbosa et al. (2003).

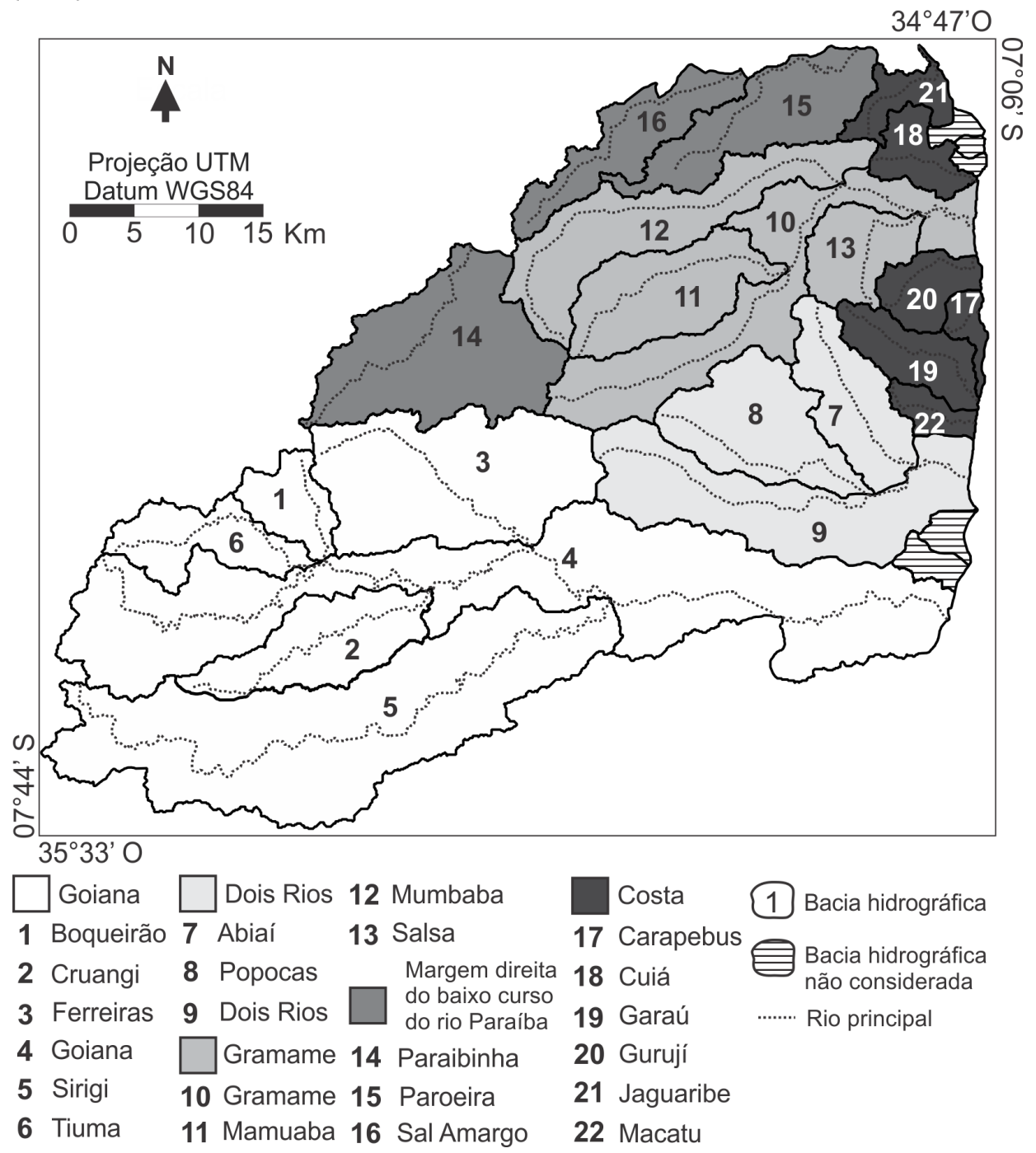

Figura 2. Mapa-índice das bacias hidrográficas utilizadas para a aplicação dos índices morfométricos. 


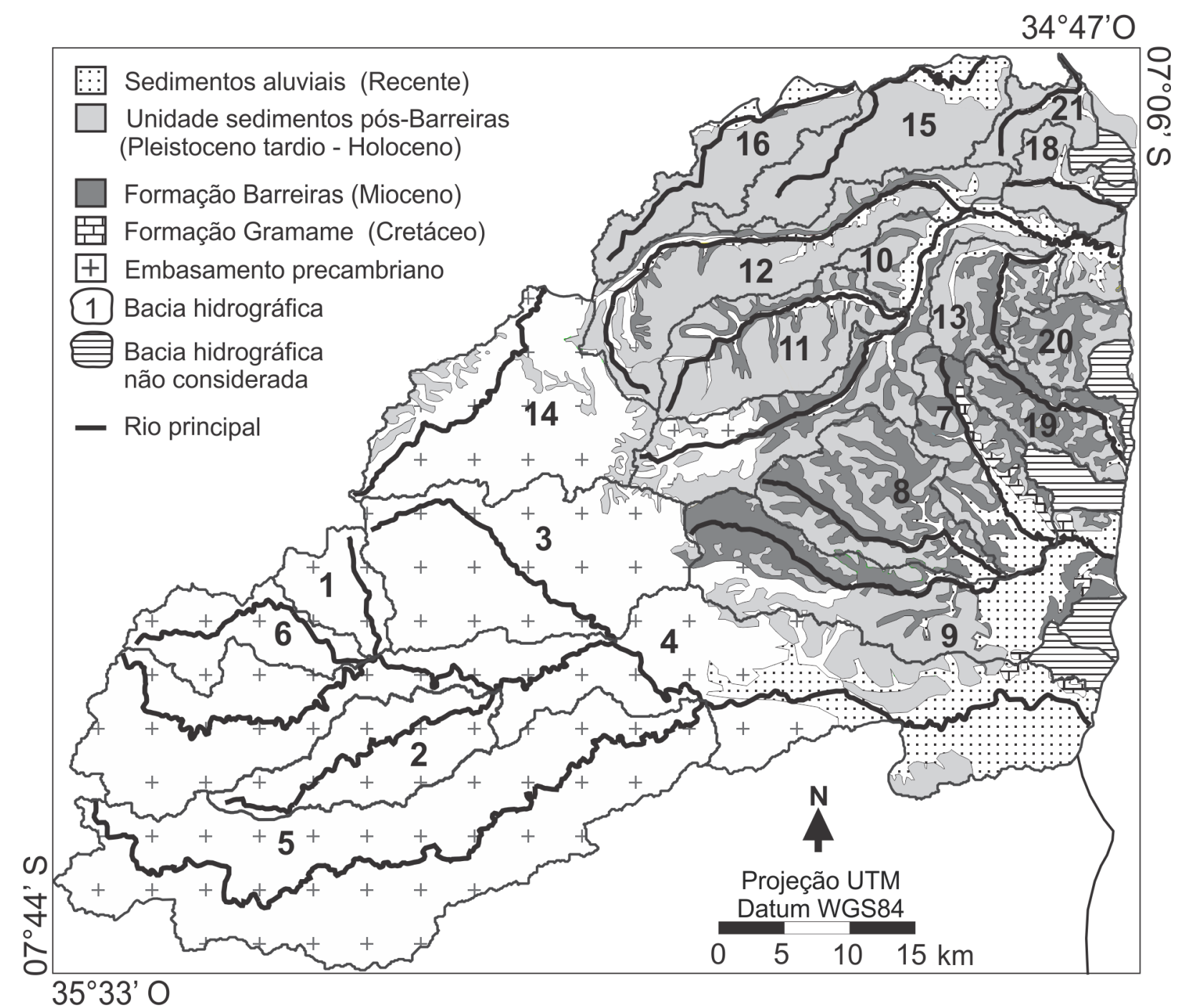

Figura 3. Unidades geológicas da área de estudo sobrepostas pela drenagem principal e bacias apresentadas no mapa-índice na fig. 2.

A extração da drenagem foi realizada com implementação dos procedimentos disponíveis no ArcGIS 9.1. A ferramenta ArcHydro Tools disponibiliza a extração automática de drenagem a partir dos seguintes procedimentos: i) aplicação do comando fill sinks, que confere a consistência da drenagem, eliminando possíveis áreas com ausência de informação que ocasionam retenção de fluxo; ii) cálculo da direção de fluxo (flow direction), baseado no método D8; iii) obtenção da matriz com acumulação de fluxos; iv) geração da rede de drenagem, onde é definido o tamanho mínimo da bacia hidrográfica através da indicação do número de células pelo usuário; v) segmentação de rede de drenagem; vi) delimitação da grade de bacias; vii) conversão da grade para formato vetorial, obtendo os limites das bacias na forma de vetor; e viii) conversão da rede de drenagem na forma matricial em vetorial. 0 resultado da aplicação destes procedimentos foi a geração das sub-bacias de drenagens no formato shape. A etapa que exigiu maior interferência do usuário correspondeu ao cálculo de di- reção de fluxo, visto que foi necessário que o limiar (número de células) indicado correspondesse ao nível de detalhamento pretendido. A partir de testes, o valor escolhido para o número de células mínimo foi 100, para as linhas de drenagem, e 5000, para os limites de bacias hidrográficas.

Para aplicação do índice $R D E$, inicialmente proposto por Hack (1973), foi utilizado o plano de informação contendo os rios principais das bacias hidrográficas em formato vetorial (Fig. 2). Cada segmento de drenagem recebeu um identificador (ID) para compatibilizar a associação entre os processamentos realizados em SIG e demais cálculos em planilha eletrônica. Na primeira etapa, foram obtidos os valores de $R D E$ total para cada rio e extraídas as cotas altimétricas dos pontos de nascente e de foz de cada drenagem, e a extensão total de cada rio. Para extração altimétrica houve a inserção de pontos nas posições de nascente e foz dos devidos segmentos de drenagem. Obteve-se os valores de elevação a partir da execução de intersecção dos pontos sobre o MDE. Estes dados foram 
exportados e calculados numa planilha eletrônica. Na segunda etapa, extraiu-se os valores de $R D E$ por segmento de drenagem de cada rio principal. Este procedimento incluiu a decomposição de cada rio principal em segmentos de drenagem de extensão uniforme, cuja proporção variou de acordo com a extensão total de cada rio principal. As dimensões dos segmentos variaram de 5 a $12 \mathrm{~km}$. Posteriormente, obteve-se a cota altimétrica do ponto mais à montante e do ponto mais à jusante de cada segmento. Estes dados foram exportados, manipulados numa planilha, onde realizou-se os cálculos da amplitude altimétrica $(\Delta \mathrm{h})$, extensão de cada segmento $(\Delta \mathrm{l})$, declividade de cada segmento $(\Delta \mathrm{h} / \Delta \mathrm{l})$, e da extensão acumulada (L) a partir do ponto médio de cada segmento. A partir destes dados, foi extraído o valor de $R D E$ por segmento e obtida a sua relação com o $R D E$ total do referido rio principal utilizando-se a seguinte equação:

$$
R D E=(\Delta \mathrm{h} / \Delta \mathrm{l}) \cdot \mathrm{L}
$$

onde, "L" corresponde à distância entre o segmento para o qual o índice $R D E$ está sendo calculado e a nascente da drenagem. Para o cálculo de "L", considerou-se como ponto de partida do segmento de drenagem o ponto médio da extensão do referido segmento, até a nascente do rio (El Hamdouni et al., 2008).

Os resultados obtidos foram importados para o SIG, ambiente onde se realizou a espacialização das informações e a classificação dos segmentos segundo os valores de RDE. Quatro classes foram definidas, sendo uma de valores considerados não anômalos $(R D E<2)$ (Seeber \& Gornitz, 1983) e três que refletem valores anômalos $(2 \leq R D E<4 ; 4 \leq$ $R D E<6$ e $6 \leq R D E$ ).

A implementação do fator assimétrico ( $A f)$ foi realizada com auxílio do programa SPRING 5.2 e da planilha eletrônica. Para isso, se utilizaram os limites de bacias hidrográficas em formato vetorial e o vetor referente ao rio principal. A partir deste vetor, efetuou-se a edição para conexão do ponto de nascente ao limite da bacia hidrográfica no alto curso com base na visualização de canais com uso do MDE. Cada bacia hidrográfica foi decomposta em duas áreas, referentes às porções direita e esquerda do rio principal. 0 valor da área da porção direita de cada bacia foi dividido pela área total da bacia hidrográfica. Assim, se possibilitou a obtenção do valor de assimetria em planilha eletrônica (Equação 2):

$$
A f=100(A r / A t)
$$

onde a expressão $A r$ é a medida da área direita da bacia e $A t$ corresponde à medida da área total da bacia de drenagem. A partir do resultado, foi subtraído o valor 50 . 0 valor resultante desta subtração foi computado em módulo ( $|A f-50|)$. As bacias hidrográficas foram então classificadas em graus de intensidade de assimetria: baixa $(0<|A f-50| \leq$ $7)$, média $(7<|A f-50| \leq 15)$ e alta $(15<|A f-50|)$ (Keller \& Pinter, 2002). $O$ índice $A f$ pode indicar a existência de inclinações tectônicas em escala de bacia de drenagem, sendo aplicado em áreas relativamente extensas (Keller \& Pinter, 2002). Quanto mais distante da resultante 50 (abaixo ou acima), mais acentuado é o basculamento do terreno.

$\mathrm{O}$ índice $\mathrm{Hi}$ (integral hipsométrica) descreve a curva de distribuição de elevação do terreno de uma determinada bacia hidrográfica por meio da frequência acumulada das altitudes (Strahler, 1952). Sua obtenção foi feita utilizando-se os polígonos referentes a cada bacia hidrográfica e o MDE-SRTM em projeção UTM, datum WGS84. Os dados foram processados com auxílio do programa ArcView-GIS 3.2 e de planilha eletrônica. Na primeira etapa, o MDE foi convertido do formato GeoTiff para Grid. O dado em formato Grid foi recortado a partir do polígono de cada bacia hidrográfica. A partir de cada recorte, foi extraída a integral hipsométrica. A implementação deste processamento necessitou das informações de área da célula $\left(\mathrm{m}^{2}\right)$, referente à resolução espacial do Grid (3"); do polígono da bacia hidrográfica que contém, em seus atributos, a informação de área da bacia; e do valor de incremento de elevação (i.e., $1 \mathrm{~m}$ ) a ser considerado no cálculo. 0 resultado deste procedimento é um produto representado através de tabela em formato Dbf. Na segunda etapa, cada tabela foi exportada para uma planilha eletrônica, e foram elaborados os gráficos de curva hipsométrica e integral hipsométrica. $\mathrm{O}$ índice $\mathrm{Hi}$ representa determinada área da bacia que ainda não esteve sujeita a processos erosivos, configurando-se como indicador de diferentes estágios evolutivos do relevo (Keller \& Pinter, 2002; PérezPeña et al., 2009).Valores do $H i>0,5$, entre 0,4 e 0,5 e $<0,4$ geram curvas hipsométricas convexas, côncavo-convexas ou retilíneas, e côncavas, respectivamente. Valores de $\mathrm{Hi}$ elevados associam-se a terrenos jovens, onde a erosão é reduzida, o que sugere, embora não de maneira exclusiva, atividade tectônica recente (El Hamdouni et al., 2008). Estes autores também relacionam valores de $\mathrm{Hi}$ baixos com paisagens antigas afetadas por processos erosivos por tempo prolongado.

Para obtenção do índice de sinuosidade de frente de montanha (Smf) utilizou-se o plano de 
informação das bacias hidrográficas, a base de declividade (SN) do TOPODATA (Valeriano \& Rossetti, 2012) e o MDE. Os dados foram tratados em SIG e planilha eletrônica. Na primeira etapa, com auxílio visual do MDE e da base de declividade, identificou-se e digitalizou-se as feições denominadas frentes de montanha dentro de cada bacia hidrográfica. Para cada feição, foram delimitados dois segmentos vetoriais. Primeiramente, traçou-se, por edição vetorial, cada feição na sua forma retilínea $(L s)$, de acordo com sua conformidade geral no terreno. Na sequência, criou-se outro plano de informação vetorial, onde foi traçada a mesma feição, porém respeitando a sinuosidade existente da encosta $(L m f)$, revelada visualmente por fortes rupturas de declividade na base.

A informação de extensão (m) dos segmentos de $L s$ e $L m f$ foi exportada para uma planilha eletrônica, onde se realizou o cálculo do índice $S m f$ para cada bacia hidrográfica de acordo com a seguinte equação 3 .

$$
S m f=L m f / L s
$$

onde, $L m f$ é o comprimento da frente da montanha medida na base onde ocorre mudança de declividade; e $L s$ é o comprimento, em linha reta, da face do relevo. A atividade tectônica vertical tende a produzir faces de relevo acentuadamente retilíneas, que coincidem com falhas ou fraturas ativas (Bull \& Mc Fadden, 1977; El Hamdouni et al., 2008). Em geral, os valores que indicam possíveis faces de relevo decorrentes de processos tectônicos estão próximos a 1,0 (El Hamdouni et al., 2008).

Além dos índices morfométricos individuais acima descritos, a discriminação de áreas com diferentes graus de influência de atividade tectônica pode ser avaliada quantitativamente pela combinação desses índices (e.g., Bull \& Mc Fadden, 1977). Uma dessas combinações, que inclui a média dos índices anteriores, resultou na proposição do índice combinatório de atividade tectônica relativa (Iat) (El Hamdouni et al., 2008). O valor obtido desta razão é atribuído a classes de atividade tectônica relativa. Para aplicação deste índice foram combinadas as informações dos índices morfométricos utilizando-se planilha eletrônica. Através dos valores de categorias de intensidade tectônica (Cit) (1=alta; 2=média; 3=baixa) em cada índice, foi auferida a média do valor de Cit para cada bacia hidrográfica. Com base na média de Cit obtida em cada bacia foi possível a determinação de diferentes graus de intensidade tectônica relativa (Iat), devidamente enquadradas na proposição de El Hamdouni et al. (2008) onde a intensidade tectônica é representada em nível altíssimo (classe 1), nível alto (classes 2 e 3 ) e nível moderado (classes 4, 5 e 6 ).

\section{Resultados}

Foi possível aplicar os índices morfométricos para 22 redes hidrográficas de $3^{\underline{a}}$ ou $4^{\underline{a}}$ ordem, apresentadas no mapa-índice (Fig. 2). A análise quantitativa baseada nos diferentes índices morfométricos sugere influência tectônica na morfologia do terreno em diferentes graus de intensidade.

\section{1 Índice RDE}

0 índice $R D E$ foi aplicado para 20 rios principais da área de estudo. Foram excluídas da análise as bacias Carapebus (17) e Macatu (22), devido ao reduzido comprimento de seus rios principais, que poderia resultar em valores espúrios de $R D E$ ao longo destas drenagens. Foram definidos 75 segmentos de drenagem para toda área de estudo, que atingem uma soma de $625 \mathrm{~km}$ de extensão.

A obtenção do índice $R D E$ por segmentos revelou indícios de anomalias de drenagem em todas as bacias hidrográficas. As anomalias ocorrem tanto em segmentos do alto curso dos rios, quanto de seus cursos médios e baixos. No total, foram definidos 50 segmentos anômalos, ou seja, aproximadamente $67 \%$ do total de trechos de rio analisados. Alguns rios se destacam por apresentar grande quantidade de trechos anômalos, como os rios Cruangi, Ferreiras, Boqueirão, Gurují e Cuiá. Os segmentos de drenagem estão espacializados segundo a classificação dos segmentos de drenagem a partir dos valores obtidos na relação entre o índice de $R D E$ por segmento $(R D E S)$ e o índice de $R D E$ total (RDEt) do rio (Fig. 4). Os segmentos representados na cor verde obtiveram índice $R D E$ $<2$, portanto, não são considerados anômalos. Os segmentos considerados anômalos são os que obtiveram $R D E \geq 2$. Devido à expressiva amplitude de valores anômalos, foi possível a distinção das anomalias em índices considerados moderados $(2 \leq$ $R D E<4)$, altos $(4 \leq R D E<6)$ e altíssimos $(R D E \geq 6)$.

É constatado que na porção onde há predomínio de rochas do embasamento, 77 \% dos segmentos de rio são anômalos. Na porção do terreno onde prevalecem coberturas sedimentares, os trechos de rio anômalos perfazem 59 \% do montante da área (Fig. 3 e 4). Na observação da intensidade destas anomalias, verifica-se que, apesar de grande parte dos trechos anômalos ocorrer na porção do embasamento cristalino, os trechos que indicaram valores mais altos estão no setor onde predo- 


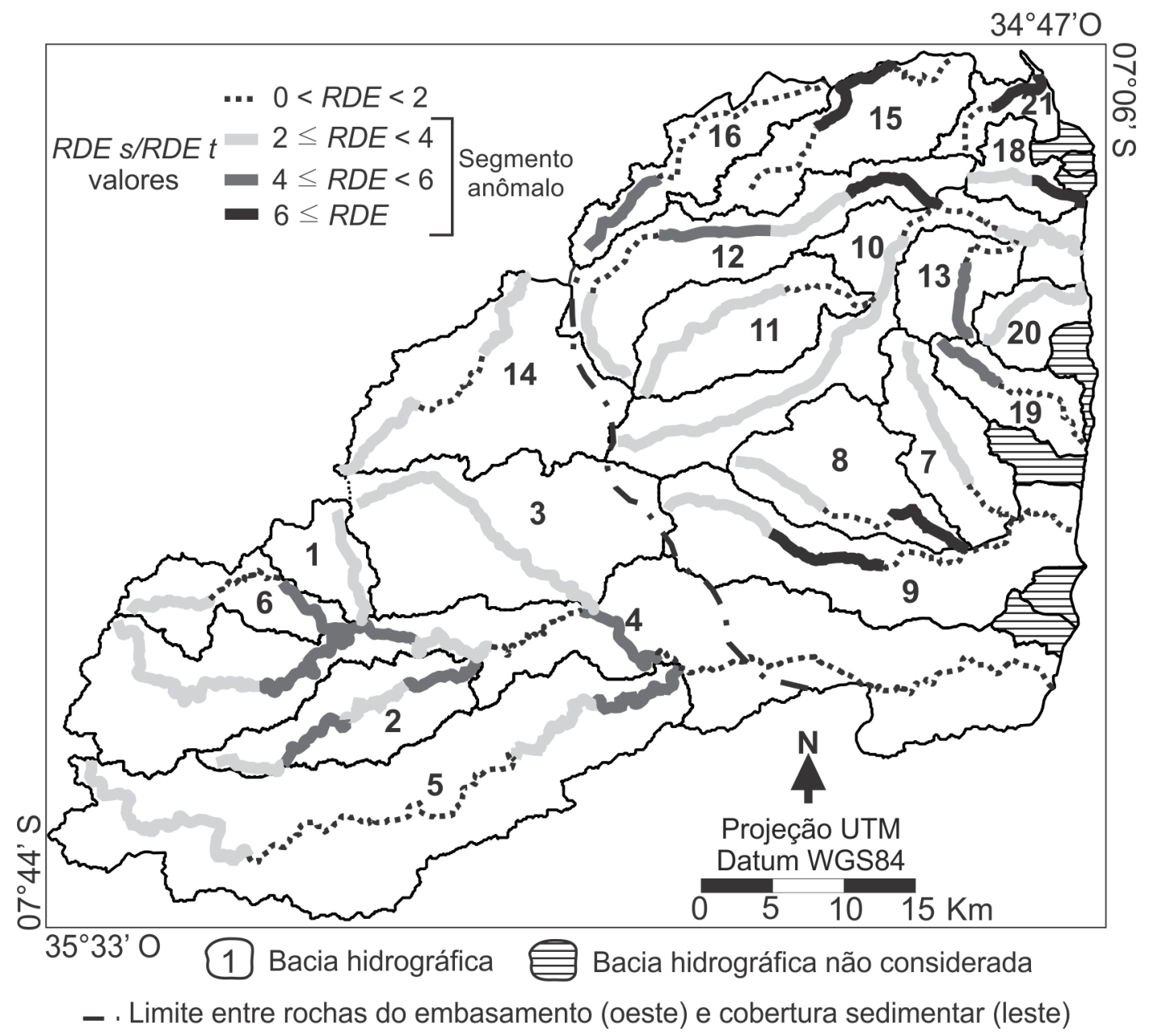

Figura 4. Segmentos de rio anômalos e não-anômalos segundo o índice RDE (RDEs = relação declividade-extensão por segmento de drenagem; $R D E t$ = relação declividade-extensão para toda extensão do rio).

minam coberturas sedimentares.

A unidade de bacias do Gramame apresenta, proporcionalmente, o maior número de anomalias, visto que $75 \%$ de seus segmentos de drenagem foram considerados anômalos. Em seguida estão as unidades do Goiana, bacias litorâneas e Dois Rios, com $71 \%, 67 \%$ e $60 \%$ de segmentos anômalos, respectivamente. As bacias da margem direita do baixo Paraíba apresentaram $44 \%$ de segmentos anômalos.

Os segmentos de drenagem que obtiveram os maiores índices $(R D E \geq 6)$ encontram-se nas bacias hidrográficas Mumbaba (12), Paroeira (15), Cuiá (18) e Jaguaribe (21), porção norte-nordeste da área de estudo. Além destas, as unidades Popocas (8) e Dois Rios (9), a sul, também apresentaram anomalia com forte intensidade. Valores altos $(4 \leq R D E<6)$ também são encontrados nos rios Sal Amargo (16), Mumbaba (12), Salsa (13) e Garaú (19), localizados na porção norte-nordeste da área de estudo.

Na porção de predomínio de rochas do embasamento são encontrados segmentos de drenagem que obtiveram alto índice, destacando-se o setor central do conjunto de bacias hidrográficas do rio Goiana, onde ocorrem segmentos dos rios Goiana, Cruangi, Tiuma e Sirigi.

No cômputo de Cit, todas as bacias hidrográficas enquadraram-se na categoria 1 de intensidade tectônica, com exceção da Salsa (13), Sal Amargo (16) e Garaú (19), que se enquadraram na categoria 2 . Pertencem à categoria 1 as bacias hidrográficas com mais de $50 \%$ da extensão do rio principal, considerada anômala e/ou com segmento (s) com valor de $R D E$ maior que 6 . As bacias hidrográficas de categoria 2 tem menos de $50 \%$ da extensão total do rio principal considerado anômalo e com segmentos com valor de $R D E$ menor que 6. Não foram reveladas bacias hidrográficas de categoria 3 , pois todos os rios analisados apresentaram anomalias.

\subsection{Fator assimétrico (Af)}

Os valores do índice $A f$ variaram de 0,73 a 26,01 . Foram reconhecidas bacias hidrográficas com baixa, média e alta assimetria, onde $A f$ variou entre 0 e 7,7 e 15, e $>15$, respectivamente (Tab. 1). 
Este índice revelou forte heterogeneidade na área, principalmente na porção leste, onde ocorre a maior parte das assimetrias médias e altas (Fig. 5). Considerando-se bacias hidrográficas individuais, constata-se que no conjunto de bacias do rio Goiana, a bacia Boqueirão (1) e Tiuma (6) apresentaram assimetrias alta e média, respectivamente, enquanto as demais tem assimetria baixa. Possíveis sentidos de basculamento revelaram diferentes orientações, para NE na bacia Tiuma e para NO na bacia Boqueirão. Drenagem fortemente direcional ocorre na bacia Ferreiras (3). No conjunto do rio Dois Rios, as três bacias hidrográficas revelaram assimetria, sendo que Abiaí apresentou assimetria de média intensidade e as unidades do Popocas e Dois Rios revelaram assimetria alta e sentidos de basculamento $\mathrm{SO}$ e NE, respectivamente. $\mathrm{O}$ conjun- to de bacias hidrográficas do rio Gramame apresenta assimetria baixa no setor central. No entanto, nas bacias Mamuaba (11) e Mumbaba (12), a assimetria é de média intensidade, com possíveis setores de basculamento para N/NO. A bacia hidrográfica do Salsa (13) é a única com assimetria alta neste conjunto. As bacias hidrográficas da margem direita do baixo Paraíba tem assimetria alta, sendo que as bacias Paraibinha (14) e Paroeira (15) revelaram os maiores valores deste índice para a área de estudo. As três sub-bacias sugerem basculamentos para NO, onde se encontra o rio Paraíba. As bacias litorâneas tem, na porção norte, assimetria baixa, e na porção leste, assimetria média, com exceção da bacia Gurují (20), que sugere basculamento para NO.

Os mesmos limiares considerados para defi-

Tabela 1. Índice $A f$ e variáveis consideradas no seu cálculo para as sub-bacias hidrográficas da área de estudo.

\begin{tabular}{|c|c|c|c|c|c|}
\hline Bacia hidrográfica & $\begin{array}{l}\text { Área da bacia } \\
\text { (direita) km² }\end{array}$ & $\begin{array}{l}\text { Área da bacia } \\
\text { (esquerda) km² }\end{array}$ & $A f$ & $|A f-50|$ & Cit \\
\hline Boqueirão (1) & 38,982 & 13,352 & 74,49 & 24,49 & 1 \\
\hline Cruangi (2) & 65,610 & 54,117 & 54,80 & 4,80 & 3 \\
\hline Ferreiras (3) & 119,372 & 144,114 & 45,30 & 4,70 & 3 \\
\hline Goiana (4) & 314,101 & 283,327 & 52,58 & 2,58 & 3 \\
\hline Sirigi (5) & 270,398 & 209,605 & 56,33 & 6,33 & 3 \\
\hline Tiuma (6) & 50,248 & 33,510 & 59,99 & 9,99 & 2 \\
\hline Abiaí (7) & 60,344 & 41,284 & 59,38 & 9,38 & 2 \\
\hline Popocas (8) & 37,245 & 99,212 & 27,29 & 22,71 & 1 \\
\hline Rio dos Rios/Murumba (9) & 164,529 & 61,095 & 72,92 & 22,92 & 1 \\
\hline Gramame (10) & 109,083 & 112,321 & 49,27 & 0,73 & 3 \\
\hline Mamuaba (11) & 78,907 & 49,521 & 61,44 & 11,44 & 2 \\
\hline Mumbaba (12) & 107,567 & 71,565 & 60,05 & 10,05 & 2 \\
\hline Salsa (13) & 20,984 & 47,449 & 30,66 & 19,34 & 1 \\
\hline Paraibinha (14) & 170,796 & 53,898 & 76,01 & 26,01 & 1 \\
\hline Paroeira (15) & 99,011 & 32,844 & 75,09 & 25,09 & 1 \\
\hline Sal Amargo (16) & 67,147 & 28,073 & 70,52 & 20,52 & 1 \\
\hline Carapebus (17) & 10,067 & 7,377 & 57,71 & 7,71 & 2 \\
\hline Cuiá (18) & 19,707 & 22,998 & 46,15 & 3,85 & 3 \\
\hline Garaú (19) & 41,012 & 22,175 & 64,91 & 14,91 & 2 \\
\hline Gurují (20) & 30,482 & 14,939 & 67,11 & 17,11 & 1 \\
\hline Jaguaribe (21) & 20,010 & 16,590 & 54,67 & 4,67 & 3 \\
\hline Macatu (22) & 13,690 & 9,745 & 58,42 & 8,42 & 2 \\
\hline
\end{tabular}

*Obs.: As células com sombreamento cinza claro = assimetria baixa, cinza moderado = assimetria média, e cinza escuro = assimetria alta.

\section{3 Índice hipsométrico (Hi)}

Os resultados da aplicação deste índice estão representados nos gráficos referentes à integral hipsométrica de cada bacia hidrográfica (Fig. 6 e Fig. 7). Juntamente aos gráficos, é apresentado o valor absoluto da integral hipsométrica $(H i)$. A interpretação foi fundamentada na análise subjetiva da curva hipsométrica e no valor de $H i$.

Em relação às feições da curva hipsométrica, geralmente a linha com tendência à retilinearidade, principalmente no setor médio e inferior do gráfico, sugere forte equilíbrio entre processos erosivos e deposicionais, indicativo de baixa influência tectônica. As formas convexas no setor superior, a presença associada de feição convexa a côncava, e principalmente, a feição convexa no setor inferior, representam desequilíbrio entre os processos erosivos e deposicionais (Strahler, 1952). Estas feições sugerem forte influência tectônica 


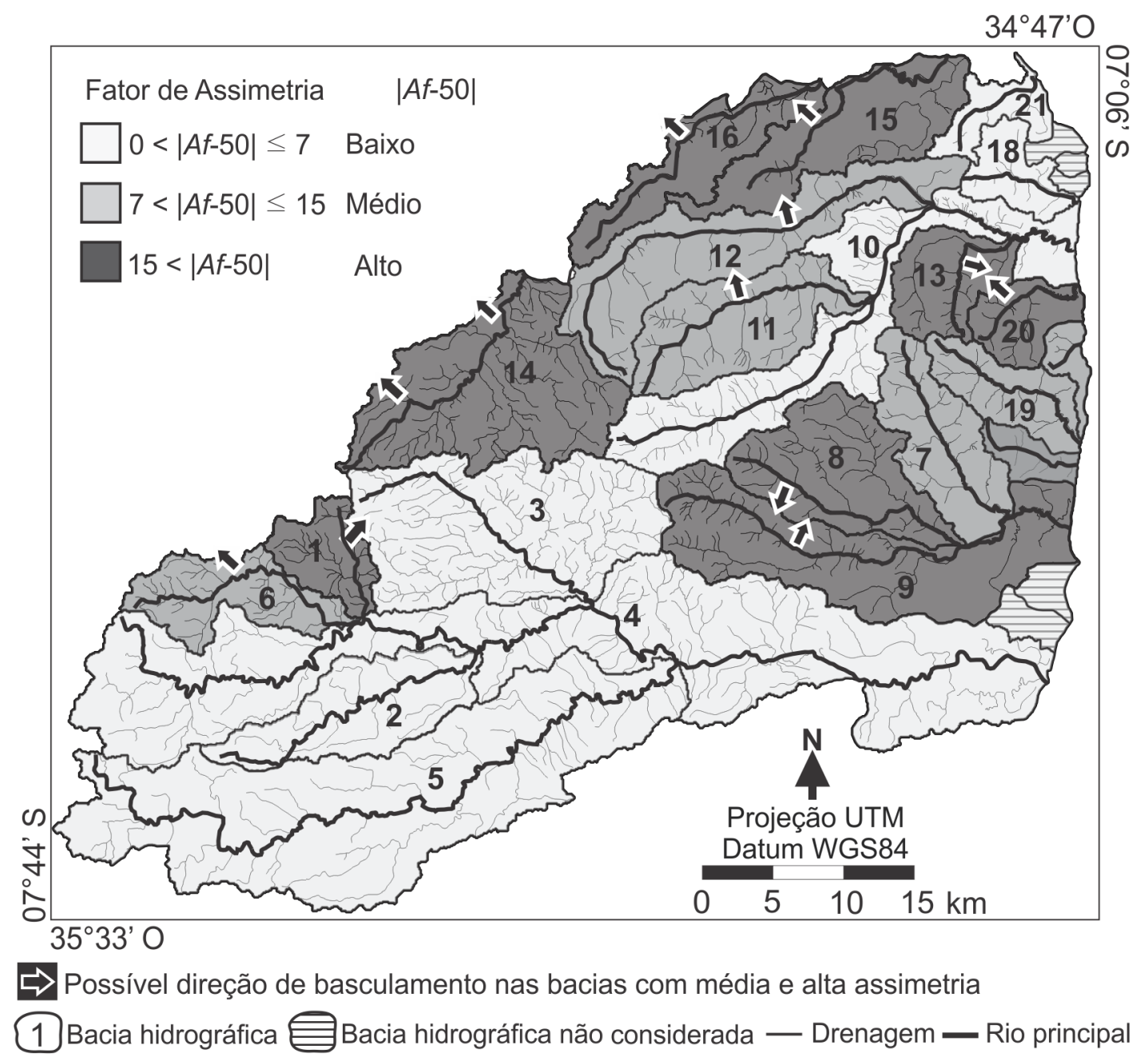

Figura 5. Fator de assimetria ( $A f$ ) para as sub-bacias hidrográficas da área de estudo.

na evolução da bacia hidrográfica. Em relação ao índice absoluto de $H i$, os altos valores indicam que suas porções mais elevadas foram pouco erodidas; portanto, sugerem paisagem jovem que pode ser decorrente de influência de atividade tectônica. De modo geral, valores superiores a 0,5 condizem com áreas de alta intensidade, valores entre 0,4 e 0,5 indicam média intensidade e valores inferiores a 0,4 sugerem baixa intensidade de influência tectônica. Esses valores foram considerados na atribuição de categorias de intensidade tectônica, indicadas na porção superior direita dos gráficos das figuras 6 e 7.

Numa análise ampla, o índice $H i$ indicou que 10 bacias hidrográficas tem características compatíveis com baixa influência tectônica, sendo que quatro estão presentes na bacia Goiana: sub-bacia hidrográfica Boqueirão, Goiana, Sirigi e Tiuma. Além destas, as sub-bacias hidrográficas de Abiaí, Dois Rios, Gramame, Salsa, Garaú e Macatu também revelaram comportamento sugestivo de intensidade de atividade tectônica baixa. Bacias com influência de atividade tectônica moderada ocorrem em diversas porções da área de estudo, incluindo as sub-bacias Cruanji, Ferreiras, Popocas, Mamuaba, Mumbaba, Paraibinha, Paroeira, Carapebus, Cuiá e Guruji. 0 índice hipsométrico revelou intensidade tectônica alta nas bacias Sal Amargo e Jaguaribe, presentes na porção norte-nordeste da área de estudo.

Para demonstrar a eficiência da aplicação do índice $H i$, é apresentado um paralelo entre as bacias hidrográficas de Sal Amargo (16) e Garaú (19) (Fig. 8), que tem particularidades dos terrenos denotando intensidade tectônica alta e baixa, respectivamente. A bacia Sal Amargo possui dois patamares altimétricos distintos e com expressiva quebra de relevo entre o médio e baixo curso; além disso, o grau de dissecação do relevo é muito baixo. Em contraponto, a bacia Garaú tem situação inversa, sem predominância de patamares altimétricos, 0 que indica relevo com alto grau de dissecação.

\subsection{Sinuosidade de frente de montanha (Smf)}

Os setores da área de estudo onde foi aplicado o índice $\operatorname{Smf}$ contém feições de relevo retilíneas, caracterizadas por escarpas com forte ruptura 

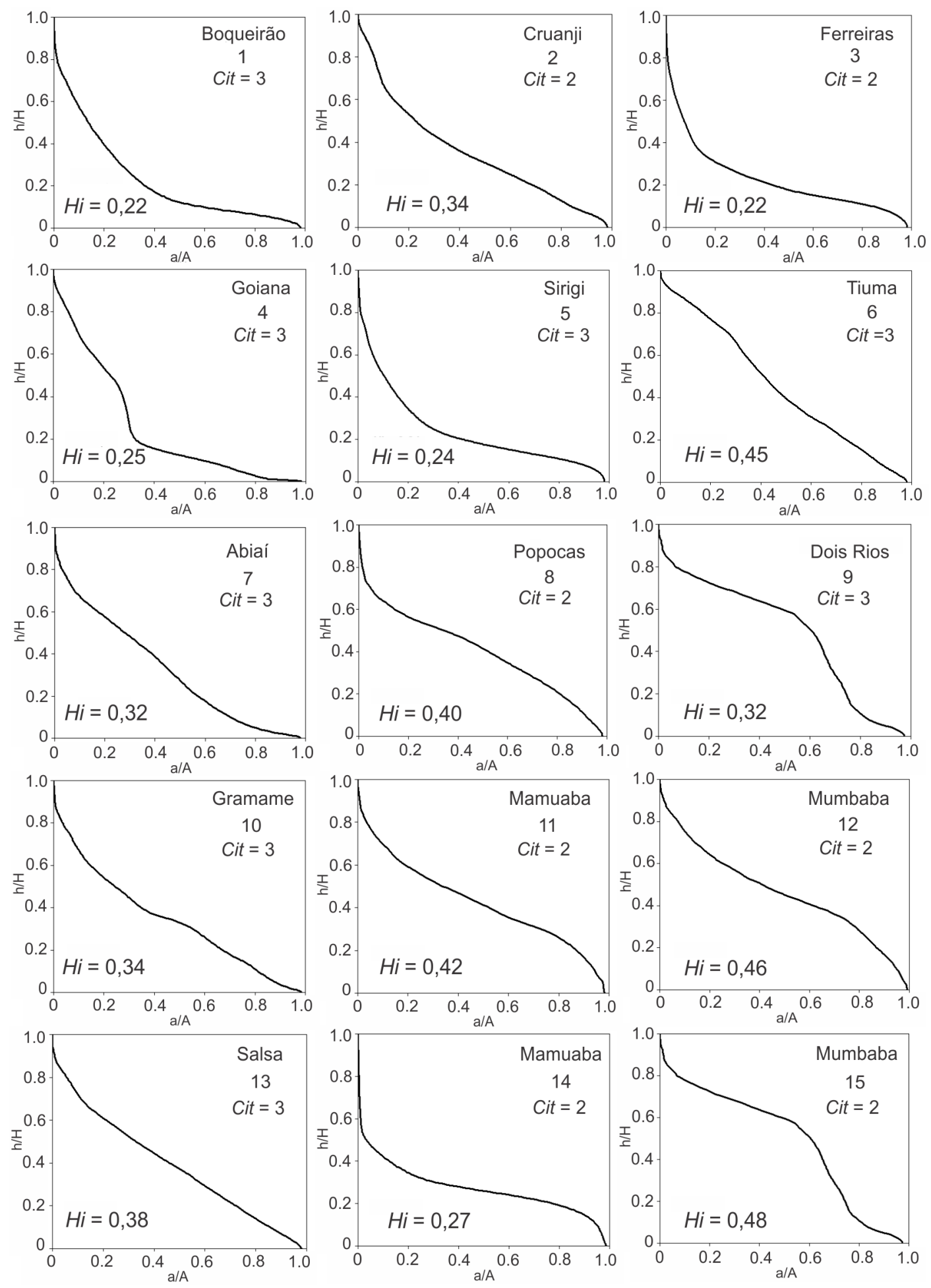

Figura 6. Curvas hipsométricas referentes às sub-bacias hidrográficas pertencentes às bacias dos rios Goiana, Dois Rios, Gramame e bacias da margem direita do baixo rio Paraíba. ( $\mathrm{A}$ = superfície total da bacia, a = área dentro da bacia acima de uma determinada cota de elevação (h), H = máxima elevação da bacia hidrográfica; Cit = categoria de intensidade tectônica atribuída e $H i=$ valor absoluto de integral hipsométrica).

de declive e que se destacam dentro dos limites de cada sub-bacia hidrográfica. A maioria das sub-bacias hidrográficas revelou mais de uma feição com relevância para implementação do cálculo. Assim, foi necessária a obtenção da média dos índices avaliados nestas bacias. Os setores estão apresentados para a porção leste (Fig. 9) e oeste (Fig. 10) da área de estudo pelas designações A, B, C ou D, no caso de existência de mais de uma feição avaliada na bacia hidrográfica, e sem designação, no caso de existência de apenas uma feição calculada na unidade.

A maior parte, i.e., $77 \%$, das bacias hidrográficas recebeu a categoria 2 de intensidade tectônica (Cit), ou seja, intensidade moderada. Esta intensidade foi indicada por valores de $\operatorname{Sm} f$ entre 

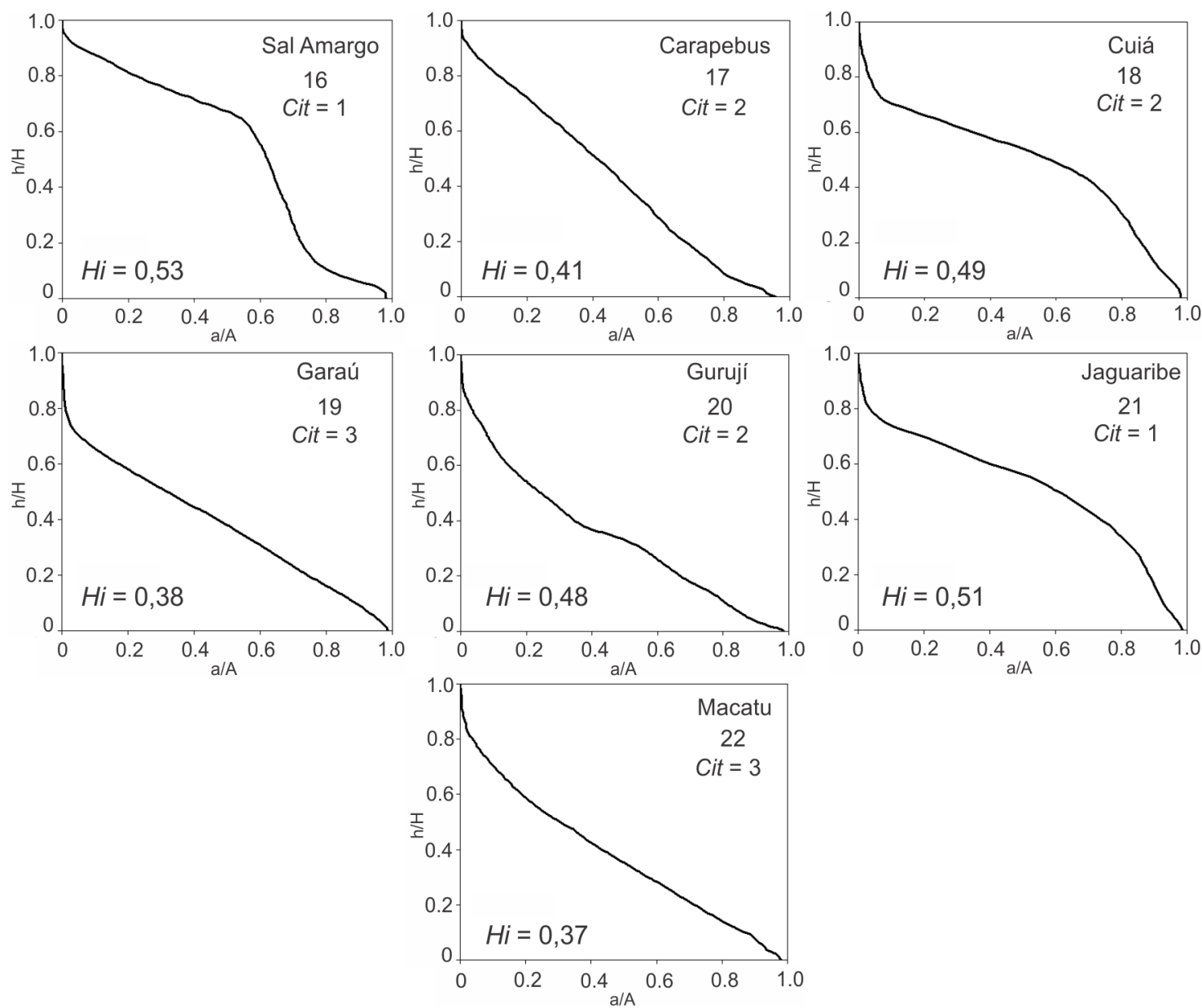

Figura 7. Curvas hipsométricas referentes às sub-bacias hidrográficas da margem direita do baixo rio Paraíba e as bacias litorâneas. $(\mathrm{A}$ = superfície total da bacia, a = área dentro da bacia acima de uma determinada cota de elevação (h), $\mathrm{H}=\mathrm{máxima}$ elevação da bacia hidrográfica; $C i t=$ categoria de intensidade tectônica atribuída e $H i=$ valor absoluto de integral hipsométrica).

a Bacia Hidrográfica Sal Amargo

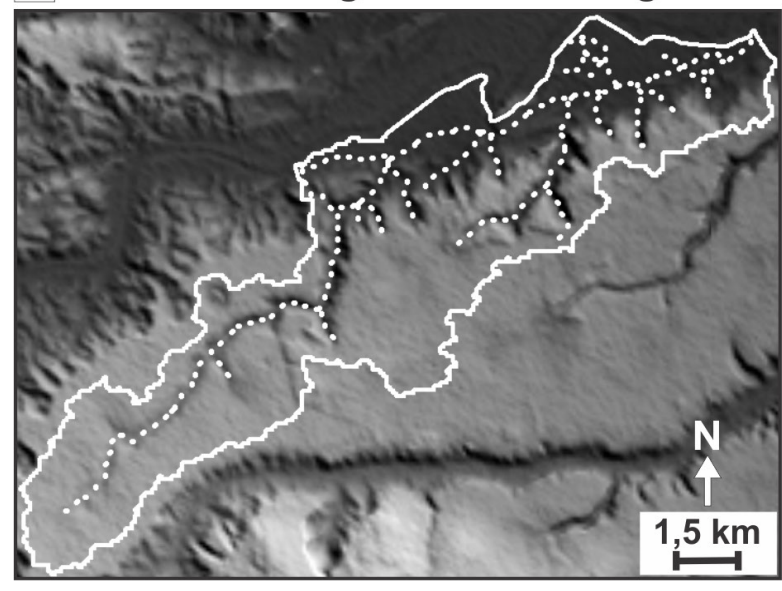

b Bacia Hidrográfica Garaú

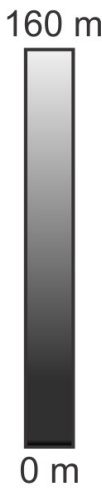

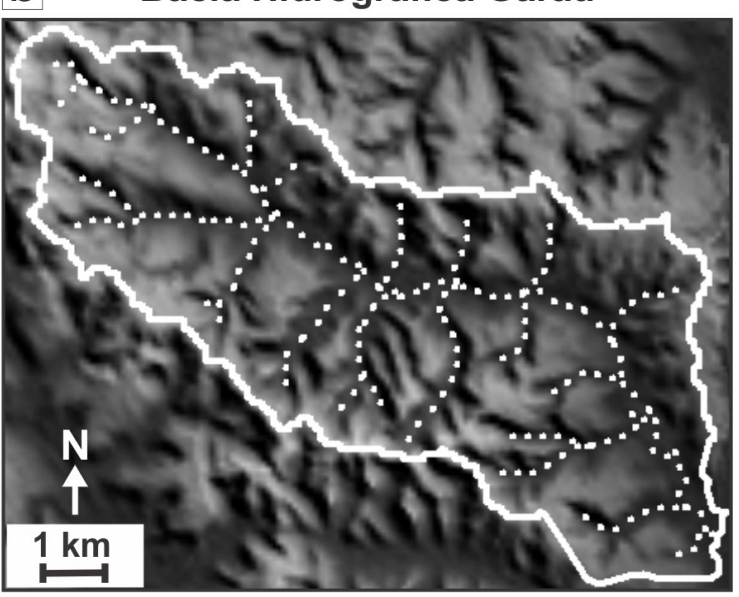

+ + Drenagem

\section{Limite da bacia hidrográfica}

Figura 8. Bacias hidrográficas representadas sobre MDE-SRTM. A) rio Sal Amargo; B) rio Garaú. (linha contínua = limite da bacia hidrográfica; linha pontilhada = drenagem).

1,1 e 1,5 (Tab. 2). Bacias com escarpas menos sinuosas foram as de Jaguaribe (21), Paroeira (15) e Tiuma (6). Esta última teve os dois setores com resultante menor que 1,1 , ou seja, indicativos de forte retilinearidade das frentes de relevo, e por isso, receberam a Cit 1 . As sub-bacias hidrográficas que apresentaram alto $S m f$ foram Sal Amargo (16) e Popocas (8).

A figura 11 mostra um contraponto entre o setor com valor de $\operatorname{Smf}$ mais baixo (Fig. 11a), i.e., 


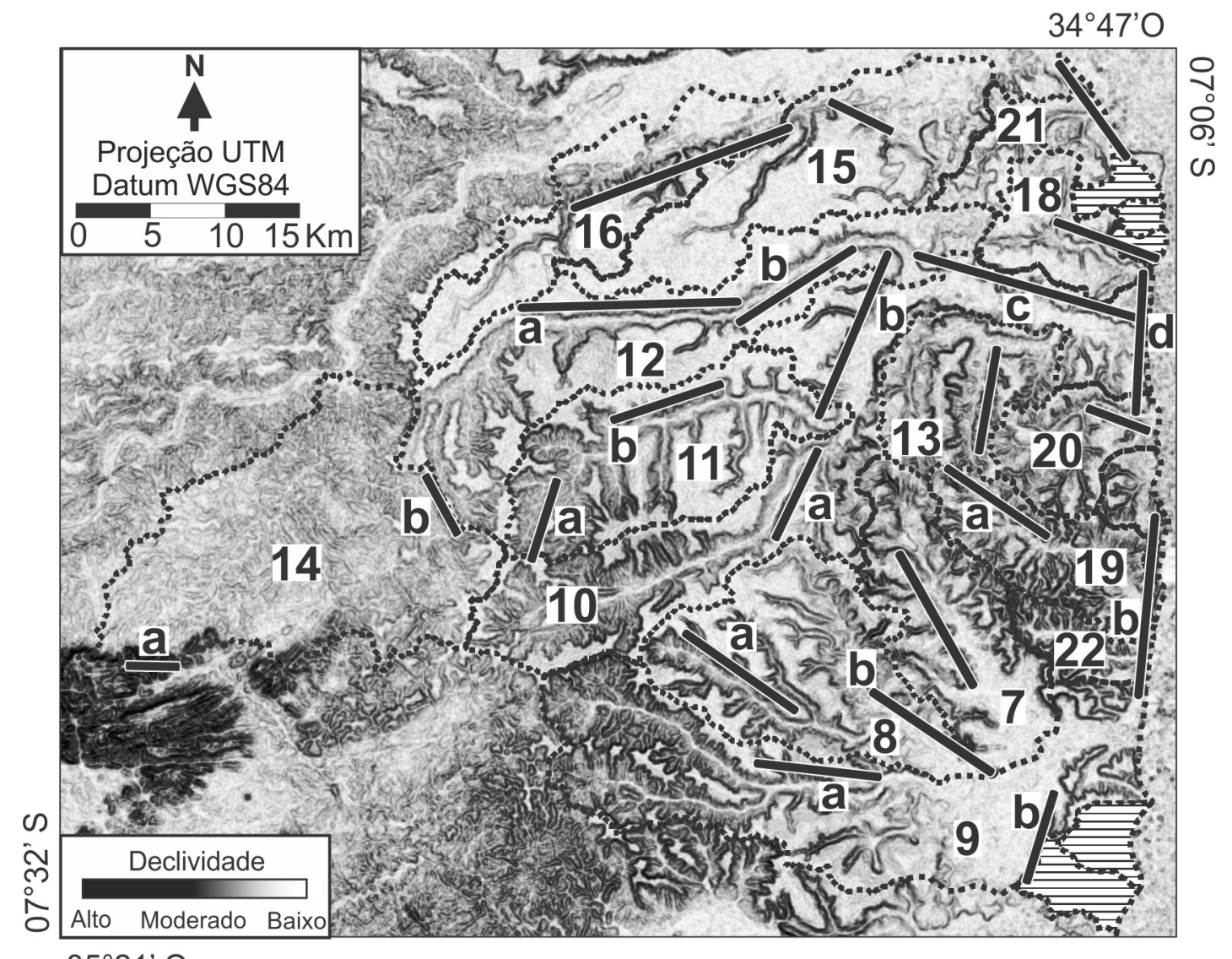

$35^{\circ} 21^{\prime} \mathrm{O}$

1 Bacia hidrográfica 0 Bacia hidrográfica não considerada — Face de relevo

$\mathbf{a}, \mathbf{b}, \mathbf{c}$ ou d: Designação da frente de montanha quando considerada mais de uma feição na bacia hidrográfica.

Figura 9. Setores de cálculo do índice Smf na porção leste da área de estudo sobre a base de declividade.

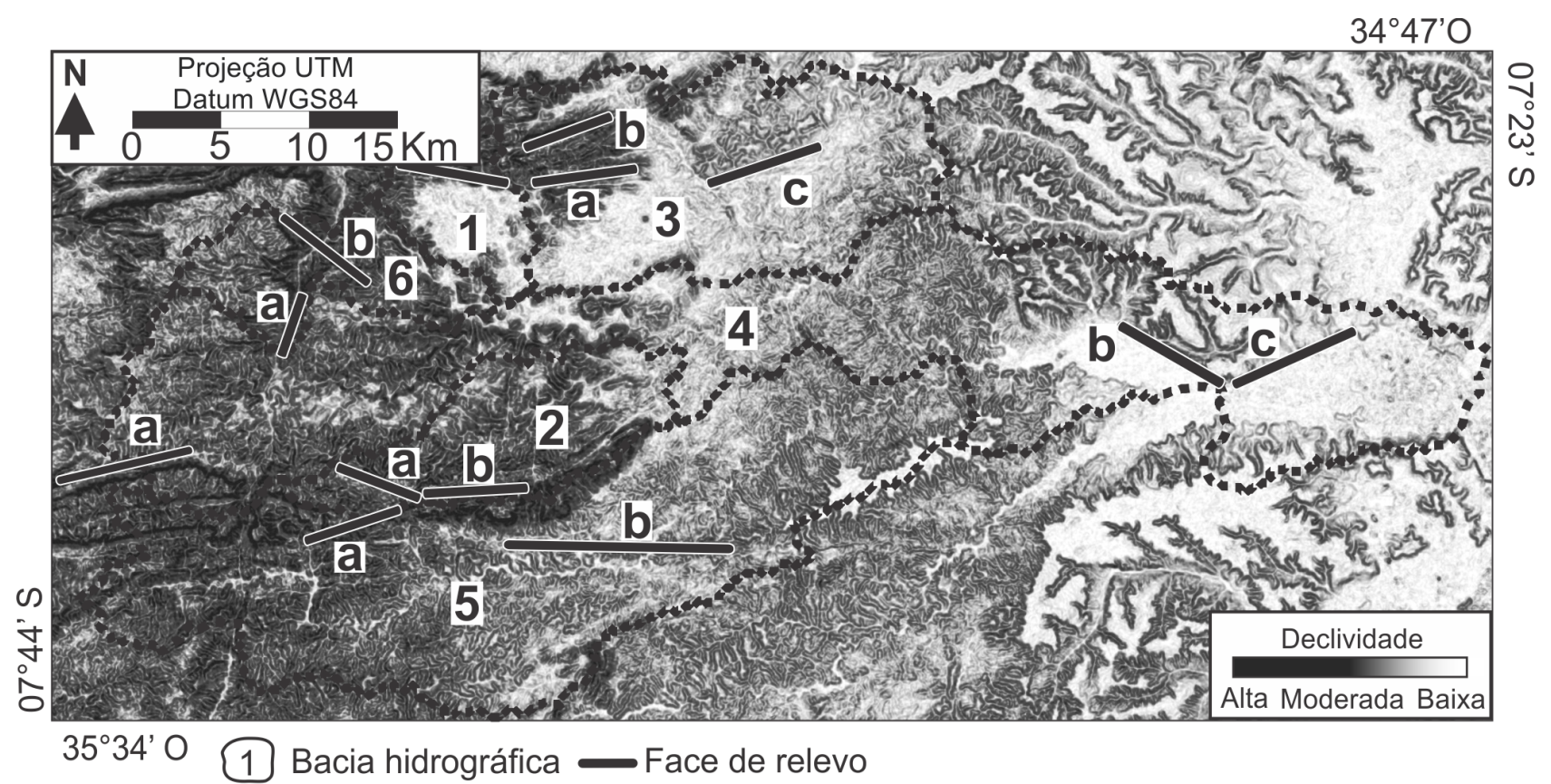

a, b, c ou d: Designação da frente de montanha quando considerada mais de uma feição na bacia hidrográfica.

Figura 10. Setores utilizados para o cálculo do índice $\operatorname{Smf}$ na porção oeste da área de estudo sobre a base de declividade. 
Tabela 2. Índice $S m f$ e variáveis consideradas no cálculo para as sub-bacias hidrográficas da área de estudo.

\begin{tabular}{|c|c|c|c|c|c|}
\hline Bacia hidrográfica & $\operatorname{Lmf}(\mathrm{m})$ & $L s(\mathrm{~m})$ & $S m f$ & $S m f$ definido para bacia hidrográfica & Cit \\
\hline Boqueirão (1) & 7490 & 6020 & 1,24 & 1,24 & 2 \\
\hline Cruanji A (2) & 5630 & 4570 & 1,23 & \multirow{3}{*}{1,16} & \multirow{3}{*}{2} \\
\hline Cruangi B (2) & 6110 & 5620 & 1,09 & & \\
\hline Ferreiras A (3) & 6300 & 5600 & 1,13 & & \\
\hline Ferreiras B (3) & 4990 & 4860 & 1,03 & \multirow[t]{3}{*}{1,13} & \multirow[t]{3}{*}{2} \\
\hline Ferreiras C (3) & 7980 & 6380 & 1,25 & & \\
\hline Goiana A (4) & 7890 & 7350 & 1,07 & & \\
\hline Goiana B (4) & 8020 & 6410 & 1,25 & \multirow[t]{2}{*}{1,14} & \multirow[t]{2}{*}{2} \\
\hline Goiana C (4) & 7880 & 7200 & 1,09 & & \\
\hline Sirigi A (5) & 6750 & 5420 & 1,25 & \multirow{2}{*}{1,31} & \multirow{2}{*}{2} \\
\hline Sirigi B (5) & 16900 & 12300 & 1,37 & & \\
\hline Tiuma A (6) & 3550 & 3390 & 1,05 & \multirow{2}{*}{1,06} & \multirow{2}{*}{1} \\
\hline Tiuma B (6) & 6290 & 5890 & 1,07 & & \\
\hline Abiaí (7) & 11200 & 8040 & 1,39 & 1,39 & 2 \\
\hline Popocas A (8) & 11700 & 6990 & 1,67 & \multirow{2}{*}{1,80} & \multirow{2}{*}{3} \\
\hline Popocas B (8) & 14900 & 7740 & 1,93 & & \\
\hline Dois Rios A (9) & 8410 & 6240 & 1,35 & \multirow{2}{*}{1,24} & \multirow{2}{*}{2} \\
\hline Dois Rios B (9) & 4360 & 3850 & 1,13 & & \\
\hline Gramame A (10) & 5160 & 4890 & 1,06 & \multirow{4}{*}{1,32} & \multirow{4}{*}{2} \\
\hline Gramame B (10) & 14100 & 9370 & 1,50 & & \\
\hline Gramame C (10) & 21200 & 13000 & 1,63 & & \\
\hline Gramame D (10) & 8180 & 7590 & 1,08 & & \\
\hline Mamuaba A (11) & 6080 & 4070 & 1,49 & \multirow{2}{*}{1,48} & \multirow{2}{*}{2} \\
\hline Mamuaba B (11) & 8380 & 5730 & 1,46 & & \\
\hline Mumbaba A (12) & 13100 & 11700 & 1,12 & \multirow{2}{*}{1,31} & \multirow{2}{*}{2} \\
\hline Mumbaba B (12) & 10600 & 7110 & 1,49 & & \\
\hline Salsa (13) & 6000 & 5190 & 1,16 & 1,16 & 2 \\
\hline Paraibinha A (14) & 2500 & 1830 & 1,37 & \multirow{2}{*}{1,27} & \multirow{2}{*}{2} \\
\hline Paraibinha B (14) & 3680 & 3140 & 1,17 & & \\
\hline Paroeira (15) & 3490 & 3180 & 1,09 & 1,09 & 1 \\
\hline Sal Amargo (16) & 19200 & 12400 & 1,55 & 1,55 & 3 \\
\hline Carapebus (17) & 12500 & 9640 & 1,30 & 1,30 & 2 \\
\hline Cuiá (18) & 6960 & 5500 & 1,27 & 1,27 & 2 \\
\hline Garaú A (19) & 8380 & 6500 & 1,29 & \multirow{2}{*}{1,29} & \multirow{2}{*}{2} \\
\hline Garaú B (19) & 12500 & 9640 & 1,30 & & \\
\hline Gurují (20) & 3420 & 2940 & 1,16 & 1,16 & 2 \\
\hline Jaguaribe (21) & 6670 & 6170 & 1,08 & 1,08 & 1 \\
\hline Macatu (22) & 12500 & 9640 & 1,30 & 1,30 & 2 \\
\hline
\end{tabular}

*Obs: $L m f=$ comprimento da frente da montanha medida em sua base onde ocorre mudança de declividade; $L s=$ comprimento, em linha reta, da face do relevo; $S m f=L m f / L s$.

na sub-bacia Ferreiras, e o mais alto (Fig. 11b), i.e., na sub-bacia Popocas. A linha preta revela a frente de relevo em linha reta e a linha branca indica a verdadeira sinuosidade da feição no terreno, que acompanha as fortes rupturas de declividade na base das encostas.

\section{5 Índice de atividade tectônica relativa (Iat)}

0 índice de atividade tectônica relativa proporcionou a combinação das categorias de intensidade tectônica atribuídas às bacias hidrográficas obtidas em cada índice geomorfométrico.

0 valor absoluto e médio das categorias de intensidade tectônica (Cit) obtido para cada bacia hidrográfica é expresso na tabela 3. A partir destes valores, foram obtidas seis classes de Iat (Fig. 12). De acordo com os valores apresentados por El Hamdouni et al. (2008), os índices de 2,5 a 2,0 indicam intensidade tectônica moderada e, nesta condição, se encaixaram as classes 4, 5 e 6 de Iat. Os valores 1,50 e 1,75, representantes das classes 2 e 3 , respectivamente, enquadram-se na qualidade de intensidade tectônica alta, e o valor 1,25 indica intensidade tectônica altíssima.

Os padrões de ocorrência das classes obtidas na área de estudo não apresentaram configuração substancialmente uniforme. No entanto, são observadas duas importantes tendências. A primeira indica que na porção $\mathrm{NE}$ - E da área de estudo 

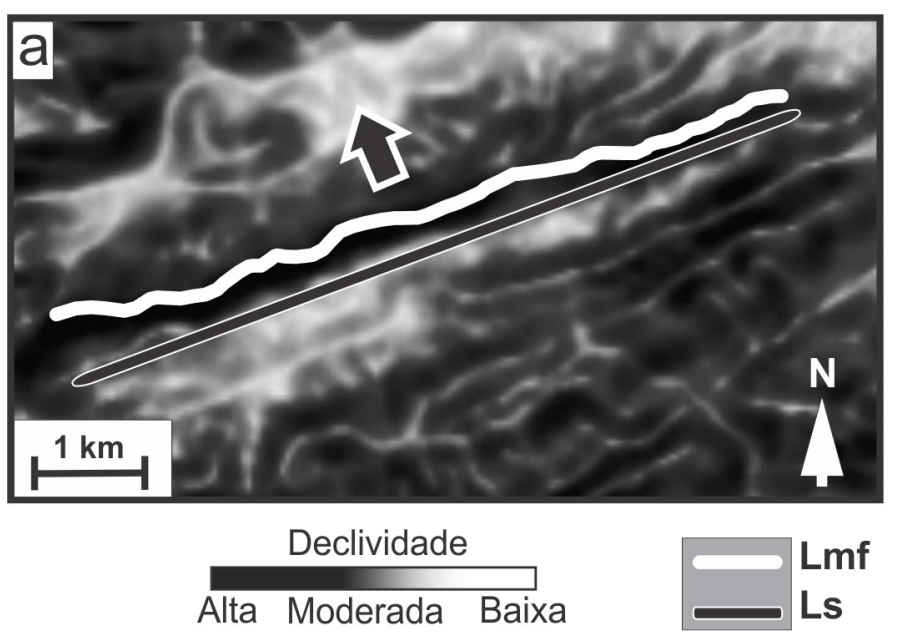

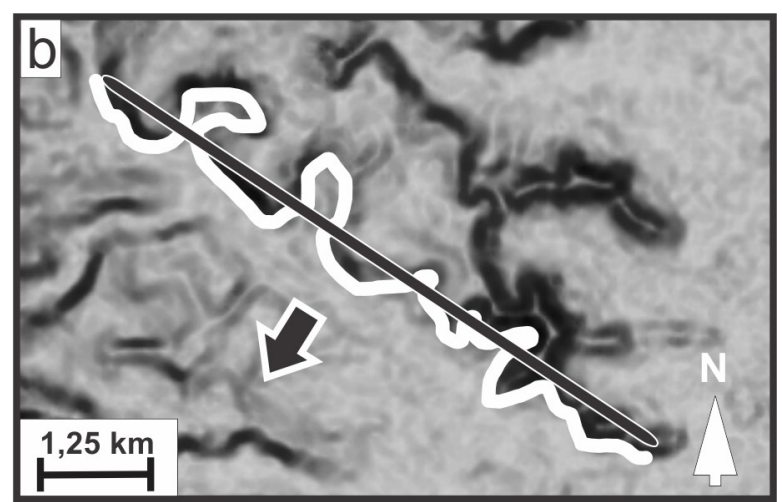

Orientação da face de relevo

Figura 11. Representação espacial das variáveis do cálculo de $\operatorname{Smf}$ sobre a base de declividade nos setores dos rios Ferreiras (A) e Popocas (B). (Lmf = comprimento da frente da montanha medida em sua base, onde ocorre mudança de declividade; e Ls = comprimento, em linha reta, da face do relevo).

há uma complexidade maior na caracterização da intensidade tectônica, visto que nesta porção são encontradas bacias hidrográficas representantes de todas as classes de intensidade tectônica aqui estabelecidas. A segunda tendência observada foi a presença de bacias com classes indicativas de intensidade tectônica alta e altíssima na porção ligeiramente à direita do rio Paraíba, ou seja, toda a faixa norte da área de estudo. Portanto, trata-se de uma área de atenção especial na avaliação morfotectônica.

\section{Discussão}

Os contatos litológicos (Fig. 3) não manifestam evidências de interferência na resposta dos índices quanto à indicação de anomalias tectônicas. Isto deve estar atrelado ao relevo da área, que controla a disposição das redes de drenagem de forma que rios com nascentes na área de cobertura sedimentar tem seu curso assentado somente sobre litologias predominantemente areníticas. Por outro lado, rios que nascem sobre o embasamento seguem seus cursos exclusivamente sobre rochas do

Tabela 3. Índice de intensidade tectônica relativa (Iat) para as bacias hidrográficas da área de estudo.

\begin{tabular}{lllllll}
\hline Bacia hidrográfica & $\boldsymbol{R D E}$ & $\boldsymbol{A f}$ & $\boldsymbol{H i}$ & $\boldsymbol{S m \boldsymbol { f }}$ & $\boldsymbol{\Sigma} \boldsymbol{C i t} / \mathbf{n}$ & $\boldsymbol{I a t}$ \\
\hline Boqueirão (1) & 1 & 1 & 3 & 2 & 1,75 & 3 \\
Cruangi (2) & 1 & 3 & 2 & 2 & 2,00 & 4 \\
Ferreiras (3) & 1 & 3 & 2 & 2 & 2,00 & 4 \\
Goiana (4) & 1 & 3 & 3 & 2 & 2,25 & 5 \\
Sirigi (5) & 1 & 3 & 3 & 2 & 2,25 & 5 \\
Tiuma (6) & 1 & 2 & 3 & 1 & 1,75 & 3 \\
\hline Abiaí (7) & 1 & 2 & 3 & 2 & 2,00 & 4 \\
Popocas (8) & 1 & 1 & 2 & 3 & 1,75 & 3 \\
Dois Rios (9) & 1 & 1 & 3 & 2 & 1,75 & 3 \\
\hline Gramame (10) & 1 & 3 & 3 & 2 & 2,25 & 5 \\
Mamuaba (11) & 1 & 2 & 2 & 2 & 1,75 & 3 \\
Mumbaba (12) & 1 & 2 & 2 & 2 & 1,75 & 3 \\
Salsa (13) & 2 & 1 & 3 & 2 & 2,00 & 4 \\
\hline Paraibinha (14) & 1 & 1 & 2 & 2 & 1,50 & 2 \\
Paroeira (15) & 1 & 1 & 2 & 1 & 1,25 & 1 \\
Sal Amargo (16) & 2 & 1 & 1 & 3 & 1,75 & 3 \\
\hline Carapebus (17) & - & 2 & 2 & 2 & 2,00 & 4 \\
Cuiá (18) & 1 & 3 & 2 & 2 & 2,00 & 4 \\
Garaú (19) & 2 & 2 & 3 & 2 & 2,25 & 5 \\
Gurují (20) & 1 & 1 & 2 & 2 & 1,50 & 2 \\
Jaguaribe (21) & 1 & 3 & 1 & 1 & 1,50 & 2 \\
Macatu (22) & - & 2 & 3 & 2 & 2,33 & 6 \\
\hline & & & & & & 3 \\
\hline
\end{tabular}




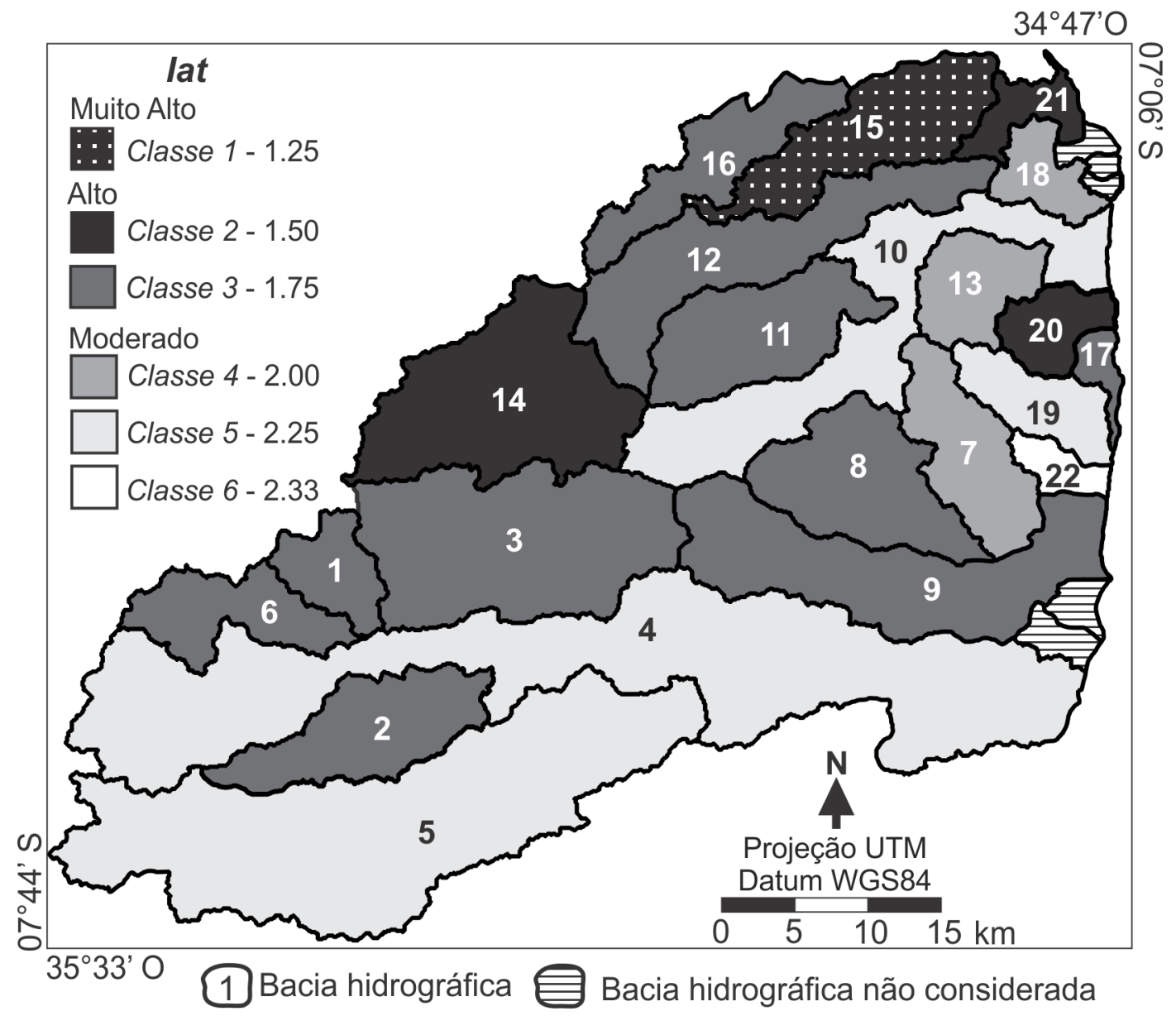

Figura 12. Classes de Iat definidas para a porção central da Bacia Paraíba.

embasamento cristalino, à exceção do baixo curso do rio Goiana. Sendo assim, não se considerou que anomalias identificadas pelos índices morfométricos tenham relação com contrastes litológicos.

Os índices morfométricos individuais extraídos do MDE-SRTM revelaram, em geral, terrenos com fortes indicativos de influência tectônica. No entanto, cada índice apresentou sensibilidade distinta. Esta constatação pode ser verificada pela própria natureza deformacional da área e a forma que o índice responde a determinada deformação. A qualidade das informações geomorfométricas obtidas é reforçada pelos seguintes aspectos técnicos: a) considerando que a área possui uma amplitude altimétrica de aproximadamente $650 \mathrm{~m}$, os dados de elevação utilizados possuem sensibilidade suficiente às variações topográficas da área já que as especificações da missão SRTM apontam com $90 \%$ de certeza que os modelos digitais de elevação foram produzidos com precisão vertical de 16 m (Rabus et al., 2003); b) o fato de a área de estudo não possuir cobertura vegetal densa é um fator positivo no que diz respeito a qualidade dos dados MDE-SRTM, já que este não sofreu interferência destes alvos como em outras áreas do Brasil com forte presença de florestas tropicais; c) os dados MDE-SRTM utilizados são compatíveis com mapeamentos em escala 1: 100.000 (Grohmann et al., 2008; Oliveira \& Paradella, 2008).

De modo geral, o índice $R D E$ mostrou o maior número de indicativos de deformação tectônica da área de estudo, com maior intensidade de influência tectônica em sistemas de drenagem instalados sobre as unidades sedimentares da porção leste; um número expressivo de anomalias foi registrado também em áreas do embasamento. Isto é atribuído ao menor grau de dissecação do relevo nas unidades sedimentares, relativamente ao embasamento, onde o terreno mostra-se mais arrasado pela atuação mais prolongada de processos erosivos ao longo do tempo. É interessante observar que valores de $R D E$ indicativos de maior deformação tectônica ocorreram em unidades sedimentares com idades geológicas mais recentes. Isto reforça a sugestão de que eventos tectônicos tenham afetado a área em idades recentes (i.e., $\mathrm{Ne}$ ógeno e Quaternário) (e.g., Bezerra et al., 2008). Em especial, a porção nordeste da área de estudo, onde predominam os sedimentos pós-Barreiras, é justamente onde estão as anomalias de $R D E$ de maior intensidade.

0 índice de assimetria não foi sensível para revelar influência tectônica na porção sul da área de estudo. Entretanto, os altos valores de $A f$ para 
toda a faixa próxima ao rio Paraíba (i.e., porção norte) sugerem forte influência de deformação tectônica, com sentidos de basculamento de blocos essencialmente equivalentes. Este índice é consistente com eventos tectônicos recentes, visto que a maior parte da área das sub-bacias assimétricas, com exceção de Tiuma e Paraibinha, ocorre sobre os sedimentos pós-Barreiras.

Na porção leste da área de estudo ocorrem várias bacias assimétricas, porém os sentidos dos basculamentos são variáveis, o que pode ser decorrente da presença de blocos de falha de menor expressão. Indício de soerguimento mais expressivo é sugerido por basculamentos entre os rios Popocas e Dois Rios, sobre a unidade da Formação Barreiras. Este basculamento não tem relação com o sentido de basculamento entre as bacias hidrográficas do Salsa e Gurují, a nordeste, onde as assimetrias devem estar associadas às feições de falha e dobra presentes no conjunto de bacias hidrográficas do Gramame.

A integral hipsométrica sugeriu influência tectônica nas bacias que indicaram possível desequilíbrio entre processos de erosão/deposição. Isto foi particularmente verificado nas bacias hidrográficas da porção leste da área de estudo: Sal Amargo, Paroeira, Mamuaba, Mumbaba, Jaguaribe e Cuia. A similaridade das feições convexas no setor inferior dos gráficos de integral hipsométrica destas bacias é condizente com curvas obtidas em áreas com soerguimentos (El Hamdouni et al., 2008). É interessante observar que este índice, similarmente ao $R D E$ e $A f$, também revelou fortes indícios de deformação tectônica no setor onde predominam as unidades sedimentares mais recentes (i.e., sedimentos pós- Barreiras).

Com relação ao índice $\operatorname{Smf}$, destaca-se que, apesar da identificação de um volume expressivo de feições retilíneas, estas estão, em geral, recuadas em relação à drenagem associada, ou seja, devem caracterizar escarpas de linha de falha. Um exemplo disto são as frentes de relevo identificadas no baixo curso dos rios Goiana e Popocas, bem como no médio curso dos rios Ferreiras, Gramame e Abiaí. Uma observação importante é que as feições retilíneas indicadas pelo índice $\operatorname{Smf}$ têm correspondência espacial com lineamentos morfoestruturais apresentados por Andrades Filho \& Rossetti (2012a). Portanto, a contribuição da aplicação deste índice está na constatação do grau de intensidade das feições, já previamente notadas no MDE pela sua retiliniaridade. A maior parte das frentes de relevo revelou grau semelhante de ação do intemperismo e erosão. No entanto, as escarpas de relevo das bacias do Paroeira, Jaguaribe e Gra- mame dão indícios de falha recente na porção nordeste da área de estudo. Estas feições ocorrem em zonas de contato entre os sedimentos pós-Barreiras, Formação Barreiras e depósitos sedimentares atuais, confirmando que estas unidades mostram efeito tectônico. As escarpas das sub-bacias do Tiuma, Cruanji e Goiana, que têm valores de $\operatorname{Smf}$ menores que 1,10 (Tab. 3), evidenciaram efeito tectônico também em áreas do embasamento cristalino da porção oeste-noroeste da área de estudo. Essas escarpas, proeminentes, podem estar relacionadas à atividade tectônica recente. Alternativamente, elas podem estar salientando estruturas antigas do embasamento.

Por fim, o índice Iat é compatível com bacias hidrográficas com indícios expressivos de deformação tectônica. Assim como já indicado pelos índices individualmente, este índice confirma que a porção leste, em especial o setor nordeste da área, com predomínio das unidades sedimentares, tem maior intensidade tectônica (Fig. 12). A porção nordeste, conjuntamente com o setor norte da área do embasamento, forma uma faixa de bacias hidrográficas com potencial influência de deformações tectônicas. Uma abundância de feições deformacionais, incluindo falhas, dobras e fraturas, foi registrada nos sedimentos pós-Barreiras e Formação Barreiras nessas áreas (Rossetti et al., 2011ab), o que é plenamente condizente com a atribuição dos valores dos índices morfométricos aqui analisados à influência tectônica.

\section{Conclusões}

Os dados do MDE-SRTM permitiram de forma eficaz a aplicação de índices morfométricos (i.e., índices $R D E, A f, H i, \operatorname{Smf}$ e Iat) como ferramenta de análise quantitativa de influência tectônica no relevo em áreas de ocorrência de rochas de idade precambriana à quaternária da Bacia Paraíba. Os índices $R D E$ e $A f$ foram aqueles que revelaram uma maior quantidade de bacias sob alta influência tectônica, e, respectivamente, os índices $\mathrm{Hi}$ e $\mathrm{Smf}$ apresentaram uma maior quantidade de bacias moderada influência tectônica. A integração destes 4 índices gerou o índice e o mapa de atividade tectônica relativa Iat que relevou áreas de maior ou menor influência tectônica na Bacia Paraíba.

A sensibilidade dos índices sugere influência de atividade tectônica recente na evolução do relevo da bacia. Os valores indicativos de maior atividade tectônica foram documentados nas unidades sedimentares mais jovens, representadas pela Formação Barreiras e pelos sedimentos pós-Barreiras. Esta constatação levou a propor que 
a Bacia Paraíba esteve submetida a deformações tectônicas em um tempo geologicamente recente que inclui o Neógeno e o Quaternário.

Agradecimentos- Este trabalho foi desenvolvido no âmbito do projeto financiado pela Fundação de Amparo à Pesquisa do Estado de São Paulo (FAPESP, Proc. 2012/106010-5), intitulado "Evolução tectonossedimentar pós-rifte na Bacia Paraíba, Nordeste do Brasil".

\section{Referências}

Andrades Filho, C.O. \& Rossetti, D.F. 2012a. Effectiveness of SRTM and ALOS-PALSAR data for identifying morphostructural lineaments in northeastern Brazil. International Journal of Remote Sensing, 33: 1058-1077.

Andrades Filho, C.O. \& Rossetti, D.F. 2012b. Caracterização Morfoestrutural da parte central emersa da Bacia Paraíba (PB). Geociências, 31: 13-29.

Andrades Filho, C.O., Rossetti, D.F., Bezerra, F.H.R., Medeiros, W.E., Valeriano, M.M., Cremon, E.H. \& Oliveira, R.G. 2014. Mapping Neogene and Quaternary sedimentary deposits in northeastern Brazil by integrating geophysics, remote sensing and geological field data. Journal of South American Earth Sciences, 56: 316-327.

Barbosa, J.A., Souza, E.M., Lima Filho, M. \& Neumann, V.H. 2003. A estratigrafia da bacia Paraíba: uma reconsideração. Estudos Geológicos, 13: 89-108.

Barreto, A.M.F., Bezerra, F.H.R., Suguio, K., Tatumi, S.H., Momose, E.F., Paiva, R.P. \& Munita, C.S., 2002. Late Pleistocene marine terrace sequences in northeastern Brazil: sea-level changes and tectonic implications. Palaeogeography, Palaeoclimatology, Palaeoecology, 179: 57-69.

Bezerra, F.H.R. 1998. Neotectonics in Northeastern Brazil. London, 208p. PhD Thesis, University of London.

Bezerra, F.H.R., Amaro, V.E., Vita-Finzi, C., Saadi, A. 2001. Pliocene-Quaternary fault control of sedimentation and coastal plain morphology in NE Brazil. Journal of South American Earth Sciences, 14: 61-75.

Bezerra, F.H.R. \& Vita-Finzi, C. 2000. How active is a passive margin? Paleoseismicity in northeastern Brazil. Geology, 28(7): 591-594.

Bezerra, F.H.R., Lima Filho, F.P., Amaral, R.F., Caldas, L.H.O. \& Costa Neto, L.X. 1998. Holocene coastal tectonics in NE Brazil. In: Stewartt, I.S. \& Vita-Finzi, C. (Eds.). Coastal Tectonics. London, Geological Society of London, p. 279-293.

Bezerra, F.H.R., Neves, B.B.B., Correa, A.C.B., Barreto, A.M.F. \& Suguio, K. 2008. Late Pleistocene tectonic-geomorphological development within a passive margin - The Cariatá trough, northeastern Brazil. Geomorphology, 1: 555-582.

Bezerra, F.H.R., Rossetti, D.F., Oliveira, R.G., Medeiros, W.E., Brito Neves, B.B., Balsamo, F., Nogueira, F.C.C., Dantas, E.L., Andrades Filho, C.O. \& Góes, A.M. 2014. Neotectonic reactivation of shear zones and implica- tions for faulting style and geometry in the continental margin of NE Brazil. Tectonophysics, 614: 78-90.

Brito Neves, B.B., Riccomini, C., Fernandes, T.M.G. \& Sant'Anna, L.G. 2004. O sistema tafrogênico terciário do saliente oriental nordestino na Paraíba: um legado Proterozóico. Revista Brasileira de Geociências, 34(1): 127-134.

Bull, W.B. \& Mc Fadden, L.D. 1977. Tectonic geomorphology north and south of the Garlock fault, California. In: GEOMORPHOLOGY SYMPOSIUM, 8., 1977, Binghamton, IAG, v. 1, p. 115-138.

El Hamdouni, R., Irigaray, C., Fernández, T., Chacón, J. \& Keller. 2008. E. A. Assessment of relative active tectonics, southwest border of the Sierra Nevada (Southern Spain). Geomorphology, 96(1-2): 150173.

Etchebehere, M.L.C., Saad, A.R., Santoni, G.C., Casado, F.C. \& Fulfaro, V.J. 2006. Detecção de prováveis deformações neotectônicas no vale do Rio do Peixe, região ocidental paulista mediante aplicação de índices RDE (Relação Declividade-Extensão) em segmentos de drenagem. Geociências , 25: 71-289.

Ferreira, J.M., Oliveira, R.T.; Takeya, M.K. \& Assumpção, M. 1998. Superposition of local and regional stresses in NE Brazil: evidence from focal mechanisms around the Potiguar marginal basin. Geophysical Journal International, 134: 341-355.

Françolin, J.B.L., Cobbold, P.R. \& Szatmari, P. 1994. Faulting in the Early Cretaceous Rio do Peixe basin (NE Brazil) and its significance for the opening of the Atlantic. Journal of Structural Geology, 16: 647-661.

Gomez, C., Delacourt, C., Allemand, P., Ledru, P., Wackerle, R. 2005. Using ASTER remote sensing data set for geological mapping, in Namibia. Physics and Chemistry of the Earth, 30(1-3): 97-108.

Grohmann, C.H. 2004. Morphometric analysis in Geographic Information Systems: applications of free software GRASS and R. Computers \& Geosciences, 30(9-10): 1055-1067.

Grohmann, C.H., Riccomini, C. \& Steiner, S.S. 2008. Aplicações dos modelos de elevação SRTM em geomorfologia. Revista Geográfica Acadêmica, 2: 73-83.

Hack, J,T. 1973. Stream-profile analysis and stream-gradient index. Journal Research of the U. S. Geological Survey, 1(4): 421-429.

Jordan, G., Meijninger, B.M.L., Van Hinsbergen, D.J.J., Meulenkamp, J.E. \& Van Dijk, P.M. 2005. Extraction of morphotectonic features from DEMs: Development and application for study areas in Hungary and Grece. International Journal of Applied Earth Observation and Geoinformation, 7: 163-182.

Keller, E.A \& Pinter, N. 2002. Active Tectonics: Earthquakes, Uplift, and Landscape. New Jersey, Prentice Hall, 362p.

Marotta, G.S. 2013. Estimativa de deformações por observações geodésicas associadas a eventos sísmicos na área de abrangência da rede SIRGAS-COM. 2013. Tese de Doutorado, Programa de Pós-graduação em Geociências Aplicadas, Instituto de Geociências, Universidade de Brasília.

Matos, R.M.D. 1992. The Northeastern Brazilian rift sys- 
tems. Tectonics, 11: 766-791.

Morais Neto, J.M. \& Alkmin, F.F. 2001. A deformação das coberturas terciárias do Planalto da Borborema (PB-RN) e seu significado tectônico. Revista Brasileira de Geociências, 31: 95-106.

Nogueira, F.C.C., Bezerra, F.H.R. \& Castro, D.L. 2006. Deformação rúptil em depósitos da Formação Barreiras na porção leste da Bacia Potiguar. Geologia USP-Série Científica, 6: 51-59.

Oliveira, D.C. \& Gomes, C.J.S. 1996. A expressão de reativacões pós-intrusao do enxame de diques Rio Ceará-Mirim (Mesozoico): Implicacões na evolucão tectônica da região. Boletim de Geociencias da Petrobras, 10(1/4): 121-145.

Oliveira, C.G. \& Paradella, W.R. 2008. An assessment of the altimetric information derived from spacebourne SAR (RADARSAT-1, SRTM3) and optical (ASTER) data for cartographic application in the Amazon region. Sensors, 8: 3819-3829.

Parcharidis, I., Kokkalas, S., Fountoulis, I. \& Foumelis, M. 2009. Detection and monitoring of active faults in urban environments: Time series interferometry on the cities of Patras and Pyrgos (Peloponnese, Greece). Remote Sensing, 1(4): 676-696.

Pérez-Peña, J.V., Azañón, J.M. \& Azor, A. 2009. CalHypso: an ArcGIS extension to calculate hypsometric curves and their statistical moments. Applications to drainage basin analysis in SE Spain. Computers \& Geosciences, 35(6): 1214-1223.

Pike, R.J. 2000. Geomorphometry - diversity in quantitative surface analysis. Progress in Physical Geography, 1(24): 1-20.

\section{Man 536}

Editores: Tatiana Silva da Silva e Paulo Alves de Souza.
Rabus, B., Eineder, M., Roty, A. \& Bamler, R. 2003. The Shuttle Radar Topographic Mission: a new class of digital elevation models acquired by spaceborne radar. ISPRS Journal of Photogrammetry \& Remote Sensing, 57: 241-262.

Rossetti, D.F., Bezerra, F.H.R, Góes, A.M., Valeriano, M.M., Andrades Filho, C.O., Mittani, J.C.R, Tatumi, S.H. \& Brito Neves, B.B. 2011a. Late Quaternary sedimentation in the Paraíba Basin, Northeastern Brazil: implications for the interplay among landform, sea level and tectonics in Eastern South America passive margin. Palaeogeography, Palaeoclimatology, Palaeoecology, 300: 191-204.

Rossetti, D.F., Bezerra, F.H., Góes, A.M. \& Brito Neves, B.B. 2011b. Sediment deformation in Miocene and post-Miocene strata, Northeastern Brazil: evidence for paleoseismicity in a passive margin. Sedimentary Geology, 235(3-4): 172-187.

Seeber, L.\& Gornitz, V. 1983. River profiles along the Himalayan arc as indicators of active tectonics. Tectonophysics, 92: 335-367.

Strahler, A.N. 1952. Hipsometric (area-altitude) analysis and erosional topography. Geological Society of America Bulletin, 63(10): 1117-1142.

Troiani, F. \& Della Seta, M. 2008. The use of the Stream Length-Gradient index in morphotectonic analysis of small catchments: A case study from Central Italy, Geomorphology, 101(1): 159-168.

Valeriano, M.M. \& Rossetti, D.F. 2012. Topodata: Brazilian full coverage refinement of SRTM data. Applied Geography, 32: 300-309. 